\title{
Soft tissue sarcomas in adults
}

\section{Editors:}

\section{Piotr Rutkowski, Iwona Kugowska}

\section{Authors:}

\section{Piotr Rutkowski ${ }^{1}$, Iwona Kugowska ${ }^{1}$, Jacek Fijuth ${ }^{2}$, Arkadiusz Jeziorski ${ }^{2}$, Janusz Ryś ${ }^{3}$, Michał Wągrodzki ${ }^{1}$, Tomasz Świtaj ${ }^{1}$, Hanna Koseła-Paterczyk ${ }^{1}$, Piotr Fonrobert ${ }^{4}$, Zbigniew I. Nowecki ${ }^{1}$, Mariusz Bidziński ${ }^{1}$, Marcin Zdzienicki ${ }^{1}$}

\author{
${ }^{1}$ Maria Skłodowska-Curie Memorial Cancer Centre and Institute of Oncology, Warsaw \\ ${ }^{2}$ Province Multidisciplinary Centre of Oncology and Traumatology, Medical University of Lodz \\ ${ }^{3}$ Maria Skłodowska-Curie Memorial Cancer Centre and Institute of Oncology, Cracow \\ ${ }^{4}$ GIST Patients Aid Association
}

\section{Key words: sarcoma, gastrointestinal stromal tumours, diagnosis, treatment, imatinib, molecular targted therapy}

\section{Table of Contents}

SOFT TISSUE SARCOMAS

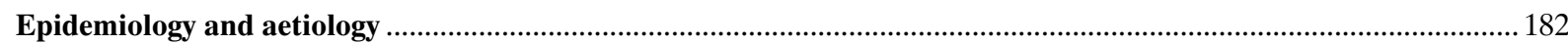

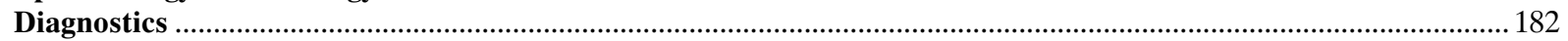

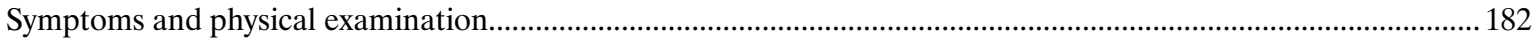

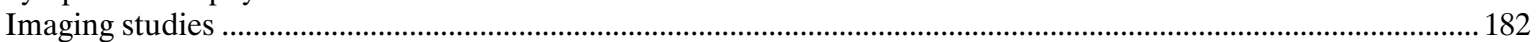

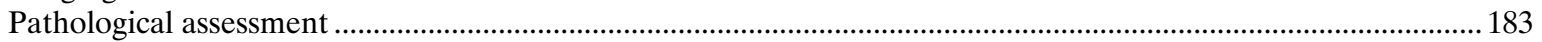

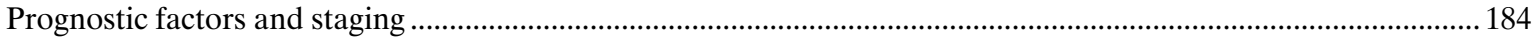

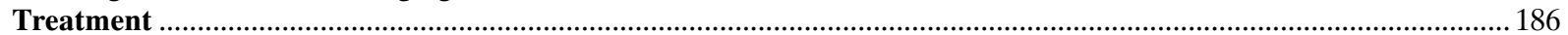

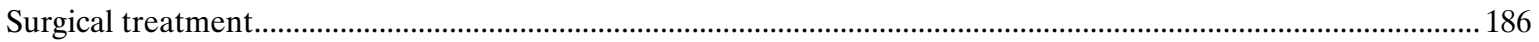

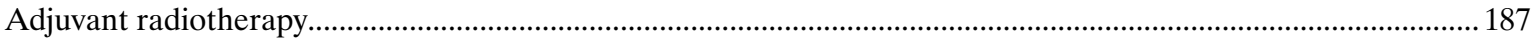

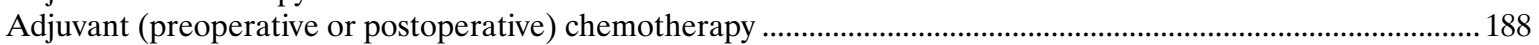

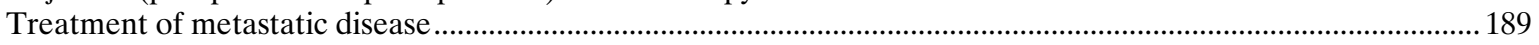

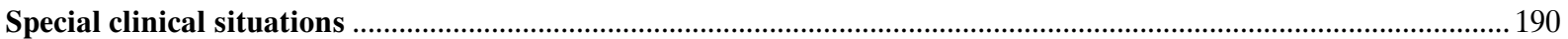

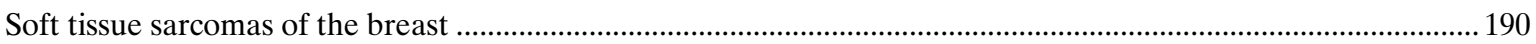

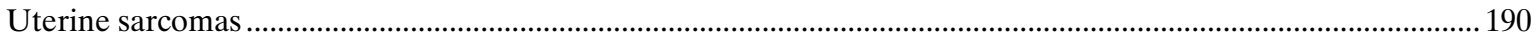

Fibromatosis (aggressive fibromatosis, desmoid-type fibromatosis) …............................................................... 190

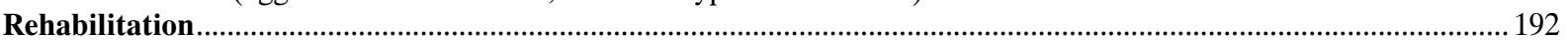

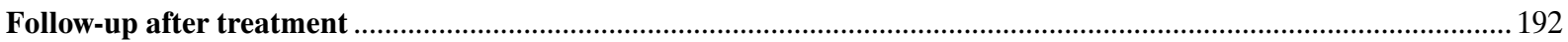

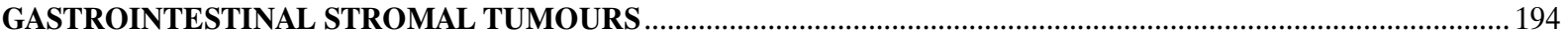

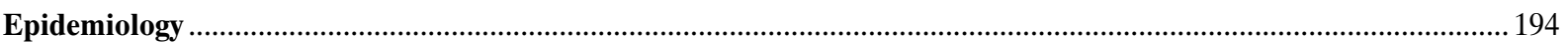

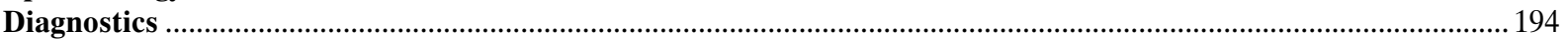

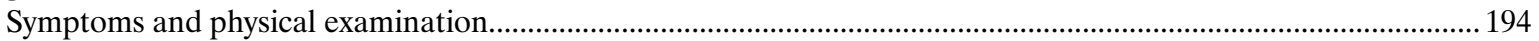

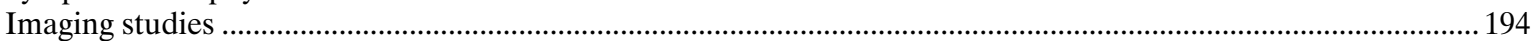

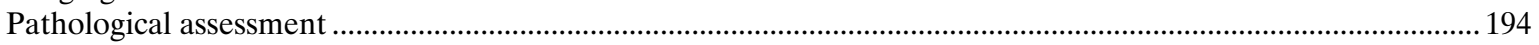

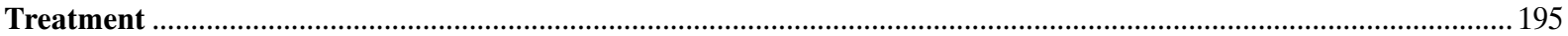

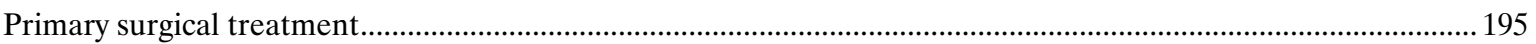

Assessment of the risk of relapse and the principles of observation after primary therapy ................................... 196

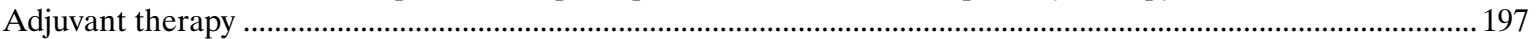

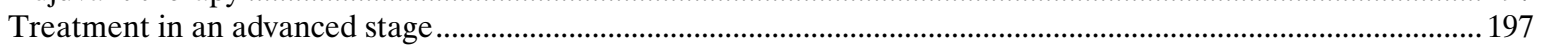

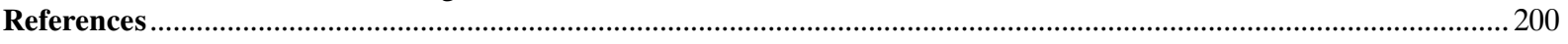


According to the authors, the guidelines contains the most justified principles of diagnostic and therapeutic procedures. They should, however, be interpreted in the context of the individual clinical situation. Recommendations do not always correspond to the current refund rules in force in Poland. In case of doubt, you should be sure of the current refund possibilities of each procedure.

\section{Soft tissue sarcomas}

Significant progress in the management of soft tissue sarcoma (STS), which has occurred in the primary treatment and in management of recurrent disease, is the result of multidisciplinary treatment administered in specialised centres. The combination of surgical treatment (primary method of therapy) with radiotherapy (RTH) and sometimes chemotherapy (CTH), and rehabilitation is a standard procedure that should be planned and carried out by multidisciplinary teams. The chances of limiting the range of resection and gaining long-term survival or cure are significantly increased. Modern combination therapy, including reconstructive procedure, allows the limb to be saved in the majority of patients with STS limb location (in reference centres amputation is done currently in less than $10 \%$ of patients). There is a steady but slow increase in the percentage of patients with STS with long-term survival (the current five-year survival rate for STS with limb localisation is 55-78\%). The prognosis at the metastatic stage of the disease is still poor (median survival approx. 12-15 months).

Positive local results only apply to patients with STS after scheduled (previous biopsy) complete primary tumour excision (microscopically free of cancer) (resection $\mathrm{R} 0$ ). In the case of correct diagnosis, most patients after complete resection require the use of complementary RTH and multi-week rehabilitation and follow-up for at least five years in the treatment centre. Improvements in the prognosis of patients are also a result of the introduction of drugs that target molecular or genetic alterations involved in STS aetiopathogenesis.

Current recommendations are useful in the treatment of STS for all locations in adults. Gastrointestinal stromal tumours (GIST) have been described separately.

\section{Epidemiology and aetiology}

In Poland, STS accounts for about $1 \%$ of all malignant neoplasms in adults (4-5 cases per 100,000, about 1000 cases per year) [1-3]. Most STS are sporadic. The greater incidence of STS is associated with certain genetic disorders (e.g. NF1 and NF2, Li-Fraumeni syndrome, Gardner syndrome, Werner syndrome), predisposing conditions (e.g. chronic lymphoedema
- Stewart-Treves syndrome), with immunosuppression and environmental factors (e.g. past irradiation or exposure to herbicides, pesticides, polyvinyl chloride, and dioxins) $[1,2]$.

\section{Diagnostics}

\section{Symptoms and physical examination}

Anatomical locations of STS include: limbs (approx. $50 \%$ ), peritoneal cavity (approx. 20\%), retroperitoneal space (approx. 15\%), head and neck region (approx. $10 \%$ ), and other locations (approx. 5\%). The clinical picture of STS is similar in many histological types, despite their significant differences.

In most cases, the only symptom of STS is a painless tumour, most commonly located under the fascia. Confirmation of the position under the fascia authorises the initial suspicion of STS, regardless of the size of the tumour, and the diagnosis can only be established on the basis of the results of microscopic examination. Soft tissue sarcomas located above the fascia may infiltrate the skin (infiltration of the bone, fascia, muscles, and nervous structures is rare). More aggressive STS can exceed natural barriers. The size of the sarcoma at the time of diagnosis is often related to its anatomical location. Particular interest should be paid to rapid (a few months) development of lesions larger than $10 \mathrm{~cm}$ or "acceleration" of growth, which may indicate a significant biological aggressiveness of the tumour. Alleged bag ("pseudocapsule") - reaction to pressure - is not an actual STS increase border. STS have a characteristic tendency to spread, mainly by blood (primarily the lungs), and (rarely) by the lymphatic nodes. In the case of a retroperitoneal or intraperitoneal site, the sarcoma may cause pain associated with compression or lead to acute complications such as obstruction, bleeding, or perforation of the gastrointestinal tract.

\section{Imaging studies}

Imaging studies are performed during the first period of diagnosis (Figure 1) to assess local tumour progression and biopsy design and disease progression analysis, differentiating and setting indications for radical surgical treatment. Imaging studies include the following:

- X-ray of the affected lesions - differentiation of deep-lying STS from primary bone sarcoma with secondary soft tissue infiltration and bone infiltration assessment and visualisation of calcifications characteristic for some types of STS;

- chest X-ray (projections posteroanterior and lateral) or computed tomography (CT) of the lungs and chest - exclusion of metastases in their most common location (STS with a high degree of histological malignancy); 


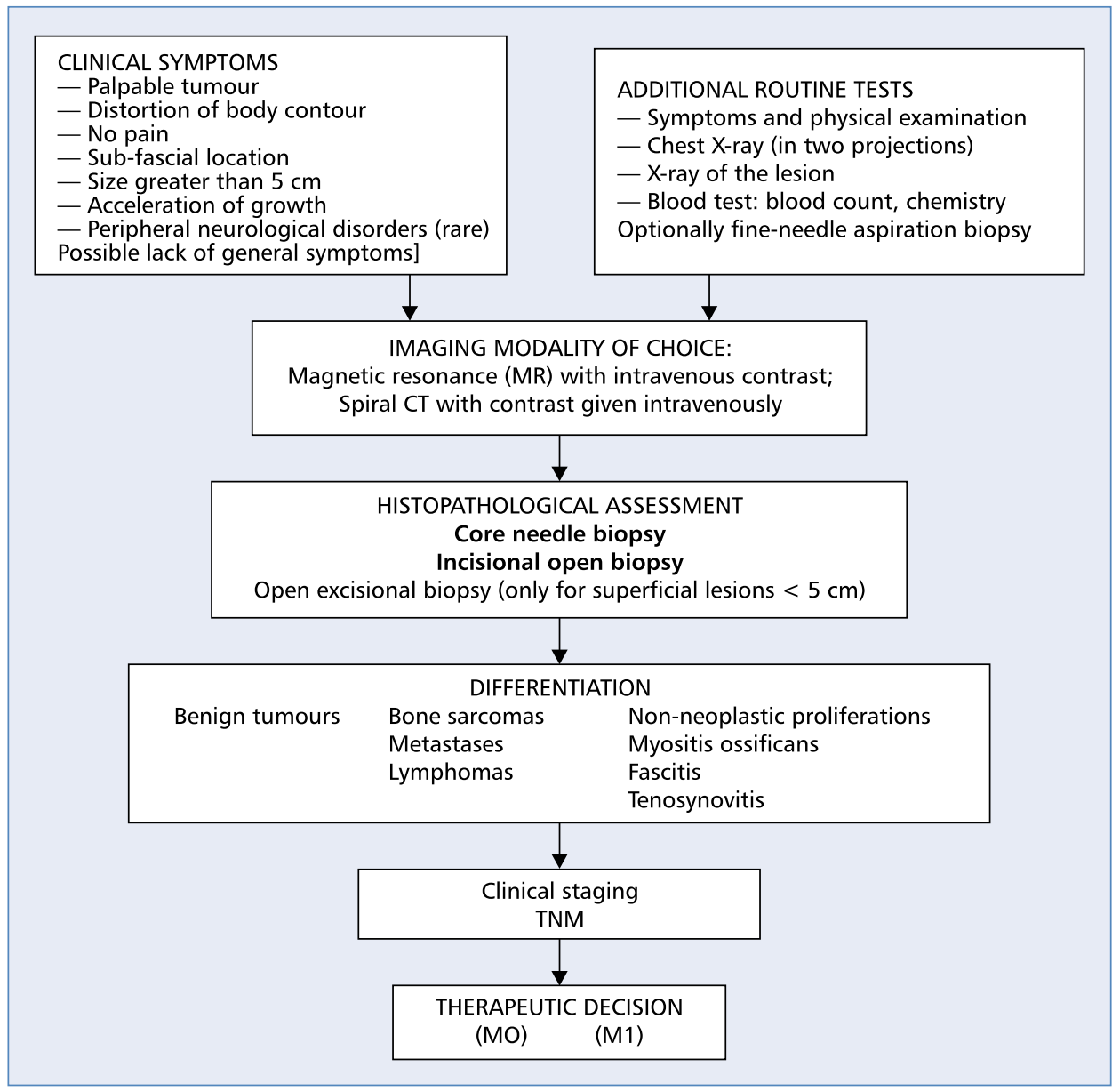

Figure 1. Diagnostic procedures for soft tissue sarcomas

- magnetic resonance (MR) with the intravenous administration of contrast - the study of choice in the evaluation of STS located in the limb and trunk, enables precise distinction of neurovascular structures, and in the sagittal and frontal area - allows the three-dimensional imaging of muscle compartments. MR is not very accurate in assessing the possible infiltration of bone by STS (the alternative is a spiral CT with contrast);

- spiral CT with contrast given intravenously and to the gastrointestinal tract — basic evaluation method for retroperitoneal and intraperitoneal STS. In certain types of STS it allows further evaluation, for example of lymph nodes in epithelioid sarcoma, synovial sarcoma, or clear cell sarcoma and abdominal cavity in myxoid/round cell liposarcoma.

\section{Pathological assessment}

After the imaging studies a biopsy should be planned and performed by an experienced surgical oncologist in collaboration with a radiologist and pathologist in a reference cancer centre.
The basis for the diagnosis and assessment of prognosis in STS is the result of histological examination of material obtained as a result of the diagnostic biopsy. The biopsy determines the proper treatment plan. It should be performed in a way that does not adversely affect local radical treatment. The basic method of collecting the material is a needle aspiration biopsy (multiple tissue extraction with a needle $\geq 14-16 \mathrm{G}$ ) and possibly an open-cut biopsy. The site of the biopsy is cut out during radical surgery. An excision biopsy can be used only in the case of superficial STS of size up to $5 \mathrm{~cm}$. It is often equivalent to "enucleation" of the tumour and contraindicated in the event of all the soft tissue tumours having a size greater than $5 \mathrm{~cm}$ and/or located under fascia, because it prevents proper pre-treatment and results in surrounding residual microscopic foci of tumour tissues and changes the compartmental location of STS. Closed biopsy is associated with a slightly higher percentage of diagnostic errors than open biopsy, while open biopsy is associated with a greater number of complications. It is recommended that a portion of the biopsy tissue be protected for cytogenetic studies and frozen to allow molecular testing. 
In the optimal treatment regimen, diagnostic biopsy, correct microscopic diagnosis, and radical treatment should be performed in the same centre. Errors in diagnosis, poor uptake of the material, bad biopsy technique, unrepresentative biopsy, and complications of biopsy, which affect the change planned treatment or change in the course of the disease, occur more frequently when the test is carried out in less experienced centres, compared with the reference centres [III, A]. The current proposals are as follows:

- diagnostic biopsy (core needle or slitting) should be performed by a surgeon experienced in the treatment of sarcomas, who then will operate on the patient;

- if the facility is not prepared for the use of combination therapy, the patient should be referred to the referral centre before biopsy. STS microscopic diagnosis must be established before determining the strategy of combination therapy based on diagnostic biopsy (not performing biopsy is a mistake) and must precede the radical management of the STS.

Diagnosis and treatment of STS in reference centres should concern patients with:

- each soft tissue tumour located under the fascia, regardless of size;

- each subcutaneous tumour of the largest size of more than $5 \mathrm{~cm}$;

- each soft tissue tumour suspected of malignancy. Histological diagnosis should be based on World Health Organisation (WHO) classification [4] and histological malignancy assessment according to the Fédération Nationale des Centers de Lutte Contre Cancer (FNCLCC) [1]. Morphological and immunohistochemical evaluations should be complemented by molecular biology studies by in situ hybrid fluorescence (FISH) and a reverse transcriptase-polymerase chain reaction (RT-PCR) and, where possible, cytogenetic studies. The results of cytogenetic studies have revealed recurrent and non-random (specific) chromosomal aberrations leading to the formation of fusion genes in T-sarcomas (translocation-related sarcomas). The protein products of these fusion genes simultaneously act as oncoproteins that stimulate cell proliferation and transcription factors that determine the differentiation of sarcoma cells (specific translocations occurring in the most common $\mathrm{T}$-sarcomas and the genes involved in the formation of specific fusion genes are shown in Tab. 1).

A precondition for the creation of these fusion genes is the earlier break in the two genes involved in the formation of a specific fusion gene. This phenomenon is used to diagnose selected STS using FISH by means of break-apart probes (Tab. 1). FISH tests using these probes can be performed on tissue sections fixed in formalin and embedded in paraffin blocks.
The pathological report of the postoperative material in the part of the macroscopic description should include: exact location of the tumour (skin, subcutaneous tissue, soft tissue under superficial fascia), macroscopic description of the tumour with three dimensions, macroscopic characteristics (macroscopic image - fat, mucus, fibrous), description of tumour areas deviating from the typical appearance, extent of necrosis, and width of surgical margins in $\mathrm{mm}$. The basic information of the microscopic part of the histopathological report is as follows: histological classification of tumours with malignancy grade, number of mitoses, extent of necrosis, and distance of tumour from surgical margins to surgical specimen (in mm); attention should be paid if tumour-free tissue margin extending in a tight fascia is satisfactory (margin $<2 \mathrm{~mm}$ in the soft tissues is insufficient, which should be explicitly noted in histopathology report).

\section{Prognostic factors and staging}

Prognostic factors are the basis for assessing the severity of the disease and planning for appropriate treatment. The most important factors affecting the prognosis in patients with sarcoma are:

- degree of histological malignancy (G, grading);

- the size of the primary tumour;

- tumour localisation (under or over fascia);

- presence of metastases;

- the state of the surgical margin;

- occurrence of recurrence.

Staging is essential in determining the prognosis and choosing the right method of treatment and in order to make a meaningful comparison of results between different centres and establish uniform criteria for clinical trials. Criteria for the proper assessment of the stage are provided by subject, imaging, and histological evaluation of the surgical material. At present, the modified system of the American Joint Committee on Cancer (AJCC)/International Union for Cancer (UICC Union Internationale Contre le Cancer) of 2010 (ed. 7) is used [6] - classification is based on tumour size (T1: $\leq 5 \mathrm{~cm}$ and T2: $>5 \mathrm{~cm}$ ) and localisation ( $\mathrm{a}$ - superficial or $\mathrm{b}$ - deep, or sub-fascial) and the presence or absence of metastasis lymph nodes and distal organs (features $\mathrm{N}$ and $\mathrm{M}$ ). Grades I-III describe STS localised or metastatic to regional lymph nodes, and Stage IV refers to metastatic disease (Tab. 2). The system according to the AJCC is not used in the staging of fibromatosis, also deep (desmoid), STS, and GIST derived from brain dura, parenchymal organs, or those having lumen (digestive tract, respiratory system). In revision 8 of the AJCC GTNM system, which will apply from 2018, a separate classification 
Table 1. Specific types of translocations and gene fusions created in the selected soft tissue sarcomas (modified from [5])

\begin{tabular}{|c|c|c|c|}
\hline $\begin{array}{l}\text { Histological subtype of } \\
\text { sarcoma }\end{array}$ & Type of translocation & Fusion gene & Gene used in FISH* \\
\hline \multirow[t]{2}{*}{ Myxoid liposarcoma } & $t(12 ; 16)(q 13 ; p 11)$ & FUS/DD1T3 & DD1T3 (CHOP), FUS, \\
\hline & $t(12 ; 22)(q 13 ; q 12)$ & EWSR1/DD1T3 & EWSR1 \\
\hline \multirow[t]{4}{*}{ Synovial sarcoma } & $t(X ; 18)(p 11 ; q 11)$ & SS18/SSX1 & SS18 (SYT) \\
\hline & $t(X ; 18)(p 11 ; q 11)$ & SS18/SSX2 & \\
\hline & $t(X ; 18)(p 11 ; q 11)$ & SS18/SSX4 & \\
\hline & $t(X ; 20)(p 11 ; q 13)$ & SS18L/SSX1 & \\
\hline \multirow[t]{2}{*}{ Alveolar rhabdomyosarcoma } & $\mathrm{t}(2 ; 13)(q 35 ; q 14) \mathrm{t}(1 ; 13)(\mathrm{p} 36 ; q 14)$ & PAX3/FOX01A PAX7/FOXO1A & FOXO1A (FKHR), \\
\hline & $t(X ; 2)(q 13 ; q 35) t(2 ; 2)(q 35 ; p 23)$ & PAX3/AFX PAX3/NCOA1 & NCOA1 \\
\hline \multirow[t]{6}{*}{ Ewing's sarcoma/PNET } & $t(11 ; 22)(q 24 ; q 12)$ & EWSR1/FLI1 & EWSR1 \\
\hline & $t(21 ; 22)(q 22 ; q 12)$ & EWSR1/ERG EWSR1/ETV1 & \\
\hline & $t(7 ; 22)(p 22 ; q 12) t(17 ; 22)(q 12 ; q 12)$ & EWSR1/ETV4 & \\
\hline & $t(2 ; 22)(q 33 ; q 12)$ & EWSR1/FEV EWSR1/SP3 & \\
\hline & $\mathrm{t}(2 ; 22)(\mathrm{q} 31 ; \mathrm{q} 12) \mathrm{t}(16,21)(\mathrm{p} 11 ; \mathrm{q} 22)$ & FUS/ERG FUS/FEV & \\
\hline & $t(2,16)(q 35 ; p 11)$ & & \\
\hline \multirow[t]{2}{*}{ Clear cell sarcoma } & $t(12 ; 22)(q 13 ; q 12)$ & EWSR1/ATF1 & EWSR1 \\
\hline & $t(2 ; 22)(q 33 ; q 12)$ & EWSR1/CREB 1 & \\
\hline \multirow[t]{2}{*}{ Low-grade fibromyxoid sarcoma } & $t(7 ; 16)(q 34 ; p 11)$ & FUS/CREB3L2 & FUS, CREB3L1, \\
\hline & $t(11 ; 16)(p 11 ; p 11)$ & FUS/CREB3L1 & CREB3L2 \\
\hline $\begin{array}{l}\text { Dermatofibrosarcoma } \\
\text { protuberans }\end{array}$ & $t(17 ; 22)(q 22 ; q 13)$ & COL1A1/PDGFB & PDGFR-COL1A1 \\
\hline $\begin{array}{l}\text { Extraskeletal myxoid } \\
\text { chondrosarcoma }\end{array}$ & $t(9 ; 22)(q 22 ; q 12)$ & $E W S-C H N(N R 4 A 3)$ & EWSR1 \\
\hline Clear cell sarcoma & $t(12 ; 22)(q 13 ; q 12)$ & EWS-ATF1 & EWSR1 \\
\hline Alveolar soft part sarcoma & $\mathrm{t}(\mathrm{X} ; 17)(\mathrm{p} 11.2 ; \mathrm{q} 25)$ & ASPL-TFE3 & TFE3 \\
\hline
\end{tabular}

*Genes used in FISH studies using commercially produced break-apart probes; PNET — primitive neuroectodermal neoplasms

Only some of the genes for which rearrangements are used in diagnostic tests are included in the table. Probes are available commercially for the identification of almost all T-sarcomas, as well as parts of connective tissue hyperplasia, which are not malignant but may mimic sarcoma (e.g. nodular fasciitis, lipoblastoma)

Table 2. Clinical stage of soft tissue sarcoma by the American Joint Committee on Cancer/Union Internationale Contra le Cancer (AJCC/UICC) 2010* [6]

\begin{tabular}{|c|c|c|c|c|c|}
\hline & G & $\mathrm{T}$ & $\mathbf{N}$ & $\mathbf{M}$ & OS \\
\hline IA, B & G1 & T1a, b; T2a, b & No & MO & About $90 \%$ \\
\hline \multirow[t]{2}{*}{$I I A, B$} & G2-3 & $\mathrm{T} 1 \mathrm{a}, \mathrm{b}$ & No & Mo & About $70 \%$ \\
\hline & G2 & $T 2 a, b$ & & & \\
\hline \multirow[t]{2}{*}{ III } & G3 & $T 2 a, b$ & NO & Mo & About $50 \%$ \\
\hline & Any $\mathrm{G}$ & Any $\mathrm{T}$ & N1 & & \\
\hline IV & Any $\mathrm{G}$ & Any $T$ & Any N & M1 & $<15 \%$ \\
\hline
\end{tabular}

$\mathrm{T}$ - tumour size (T1: tumour with maximal diameter $\leq 5 \mathrm{~cm}$; $\mathrm{T}$ : t tumour with maximal diameter $>5 \mathrm{~cm}$ ); a - superficial location (above the fascia-superficial without infiltration); $\mathrm{b}$ - deep location (sub-fascial, also retroperitoneal, mediastinal, pelvic); $\mathrm{N}-$ regional lymph nodes (N0 - absence of metastases, $\mathrm{N} 1$ - presence of metastases); M - metastases in distant organs (M0 - absence of metastases, M1 — presence of metastases); $\mathrm{G}$ - histological malignancy (G1 - low = STS well differentiated; G2 — indirect = STS median; G3 - high = STS poorly differentiated/undifferentiated); OS — estimated five-year overall survival

*UICC/AJCC Grading System includes the following types of soft tissue sarcoma: alveolar soft-part sarcoma, desmoplastic small round cell tumour, dermatofibrosarcoma protuberans, epithelioid sarcoma; clear cell sarcoma; extraskeletal chondrosarcoma; extraskeletal osteosarcoma; Ewing's sarcoma; fibrosarcoma; leiomyosarcoma; liposarcoma, malignant fibrous histiocytoma; malignant haemangiopericytoma; malignant peripheral nerve sheath tumour; rhabdomyosarcoma; synovial sarcoma; angiosarcoma; sarcoma not otherwise specified 
for sarcoma located in the retroperitoneal space (nomogram) is included; inside the abdominal cavity and the thoracic organs, and within the head and neck [7].

\section{Treatment}

The treatment of patients with STS is governed by the principle of multi-specialist therapy planning, including possible adjuvant treatment (pre- or postoperative RTH and/or CTH), necessitating treatment at specialized centres by diagnostic and therapeutic teams (consisting, at least, of a pathologist, radiologist, oncologist, radiotherapist, and clinical oncologist, and rehabilitation) [III, A].

\section{Surgical treatment}

The primary goal in treating sarcoma is to provide local disease control. Persistent cure can only be achieved by radical surgical treatment of the primary lesion, and in the case of metastases only by means of their radical surgical removal. The type of surgical treatment depends on many factors (such as the location and size of the tumour, the infiltration of the surrounding structures, and the need for reconstructive techniques). Aggressive treatment of STS located on the limbs and the use of reconstructive techniques now allow the limb to be saved in most patients. The ability to reduce the risk of recurrence (local recurrence) to less than $20 \%$ is a result of a wide margin operation outside the "pseudocapsule" area (containing squeezed and altered normal tissue surrounding the tumour altogether with tumour cells). The most important elements of the surgical technique (Tab. 3) include:

- removal of the tumour in one block with the surrounding normal tissue (en bloc resection) and the surroundings diagnostic biopsy;
- removal of the tumour covered on each side with a layer of healthy tissue. The tumour should not be visible to the operating team macroscopically;

- performing a long-cut operation ("from joint to joint"), which allows closer inspection of tendon trailers to the muscular bone of the operated limb. Soft tissue localisation in the retroperitoneal space is a particular therapeutic challenge. The most desirable is resection (in one block with adduced/adjoining organs) $[8,9]$, which is possible in $50-85 \%$ of patients. The completeness of excision impedes the anatomy, the lack of real muscle compartments, asymptomatic tumour growth larger, and infiltration of vital organs.

The principle of surgical treatment of STS is radical resection of the tumour. Recommendations for reaching a centimetre-wide margin of tumour-free tissue in practice are difficult to implement. The margin obtained is narrow in the case of anatomically resistant structures (e.g. muscle fascia, periosteum, and nerves) and may be extensive in other soft tissues (e.g. muscles, especially in the longitudinal axis of the limb). As a rule, the STS resection radicalism is evaluated by $\mathrm{R}$ classification ( $\mathrm{R} 0$ - microscopically radical resection, $\mathrm{R} 1$ - microscopically non-radical resection, R2 - macroscopically non-radical resection). $\mathrm{R} 0$ is a well planned and performed resection of STS with a microscopically unchanged healthy tissue margin, which is a prerequisite for obtaining histopathological diagnosis by biopsy. $\mathrm{R} 1$ implies that in the postoperative pathological examination a microscopic tumour infiltration was found in the surgical cutting line. Category R1 also includes all accidental resections (i.e. without prior preoperative histological verification, regardless of the circumstances and the description of the operation). In the case of $\mathrm{R} 1$ resection, a second resection can be considered if appropriate margins can be obtained without significant complications. Leaving the macroscopic lesions of

Table 3. Basic and detailed principles used in surgical treatment of sarcoma of soft tissues

\begin{tabular}{|c|c|}
\hline I. General rules: & II. Detailed rules: \\
\hline $\begin{array}{l}\text { - freedom of decision as to the scope of operations (for } \\
\text { conserving surgery, patient consent for a possible amputation) }\end{array}$ & $\begin{array}{l}\text { - careful protection of tumour ulceration or damaged } \\
\text { fragments of sarcoma }\end{array}$ \\
\hline — tumour excision in one block & — avoiding unnecessary tumour pressure \\
\hline — skin incision containing site after prior surgery (biopsy) & — fast and accurate ligation of blood vessels, the use of vascular \\
\hline — keeping the margin of healthy tissue in all directions & clips \\
\hline $\begin{array}{l}\text { - excision of the muscles of the tumour whole or with a wide } \\
\text { margin }\end{array}$ & $\begin{array}{l}\text { - manipulation in macroscopically healthy tissues } \\
\text { (i.e. "cut sarcoma without seeing it") }\end{array}$ \\
\hline $\begin{array}{l}\text { - excision of vessels and nerves covered by tumour infiltration } \\
\text { at a distance of } 3-5 \mathrm{~cm} \text { from the tumour }\end{array}$ & $\begin{array}{l}\text { - the most important task of the operation is radical excision } \\
\text { sarcoma, then you should consider the issue of possible }\end{array}$ \\
\hline $\begin{array}{l}\text { Note: in the long axis the radical is usually retained; pay } \\
\text { attention to the appropriate tissue margin in the transverse } \\
\text { dimension of the limb (especially with natural barriers such as } \\
\text { vascular adventitia, periosteum, perineurium, muscle fascia) }\end{array}$ & reconstruction \\
\hline
\end{tabular}


Table 4. General scheme of the strategy of in the treatment of soft tissue sarcoma

\begin{tabular}{|c|c|c|c|}
\hline Stage & Surgery & Radiotherapy* & Chemotherapy* \\
\hline I & + & - & - \\
\hline II & + & + & - \\
\hline III & + & + & $+/ ?$ \\
\hline IV & $? /+$ & $?$ & + \\
\hline
\end{tabular}

*According to the protocols of relevant clinical trials, with the exception of adjuvant perioperative radiotherapy or palliative chemotherapy ? - individualisation of management

sarcoma during surgery signifies resection of surgical margin $\mathrm{R} 2$. In the case of $\mathrm{R} 2$ resection, if possible, carefully planned reoperation should be proposed, if possible associated with adjuvant preoperative treatment.

Amputation in STS patients is now rarely performed ( $<10 \%$ of patients) because in most cases proper sparing operations in combination with RTH provide similar local tumour control and overall survival. The basic condition for limb preservation is the possibility of radical surgery with a low risk of local recurrence while maintaining good performance and functionality of the limb.

It should be emphasised that there is no scientific evidence to support the use of non-radical macroscopic surgical treatment (R2) in combination, provided that the combination of non-radical excision with other methods (RTH and/or CTH) will help cure the patient.

Patients with STS rarely have isolated metastases in regional lymph nodes; this concerns mainly rhabdomyosarcoma and epithelioid sarcoma, and clear cell and synovial sarcoma. The presence of lymph node metastasis is significantly adversely prognostic - these cases should be treated as spread of the disease, and the treatment plan should include preoperative CTH and RTH.

Surgical treatment of isolated lung metastases (resection saving pulmonary parenchyma) is the procedure of choice in the case of countable changes and possible resectable. The primary prognostic factor is radical resection of the metastatic disease during surgery. Metastasectomy as an isolated treatment modality is highly recommended in patients with oligometastatic disease and metastatic lung disease that has been reported metachronically over a longer period of time after primary treatment; disease-free interval should be over a year [III, A] [1, 3, 10].

It is recommended that the combination treatment be individualised in patients with STS with the following general guidelines (Tab. 4) [1, 3, 11] [II, A]:

- exclusive radical surgical treatment justified in patients with stage IA (low-grade malignancy, superficial position, size $\leq 5 \mathrm{~cm}$ ) according to TNM;

- radical surgical and adjuvant RTH pre- or postoperative (justifying STS treatment in specialised centres with RTH) - STS in other stages of TNM (IB, IIA, IIB, IIC);
- prospective clinical trials (optimally with preoperative CTH and RTH) or individualised multimodality therapy - advanced STS with presence of risk factors for spread but without metastases (high grade of G3-G4 histology and > $10 \mathrm{~cm}-\mathrm{M} 0$ ), but treatment should not be initiated outside the reference centres;

- analogous treatment to primary treatment - all recurrences (local recurrence) of STS;

- initiation of treatment with $\mathrm{CTH}$, and in case of response and with countable metastases (resectable) radicalisation of the procedure (radical excision of primary change in combination with CTH and local treatment of metastases) - STS in stage IV (N1, M1).

Therapeutic regimen is shown in Figure 2. After proper diagnosis, most patients after radical surgery (R0 resection) require supplementary $\mathrm{RTH}$ several weeks of rehabilitation and continuing check-ups at the treatment centre for at least five years.

\section{Adjuvant radiotherapy}

Randomised clinical trials have shown that the use of combination therapy in the form of a broad STS resection and adjuvant RTH allows for local tumour control in $85-90 \%$ of cases, and patient survival is no different from that achieved with amputation [II, B] [12]. There is no agreement on the sequence of irradiation and surgical treatment, and the final RTH (tele- or brachytherapy) method has not been established [13, 14]. The results of a phase III clinical trial conducted by the Canadian National Cancer Institute (NCI-C) did not show a clear advantage of preoperative over postoperative RTH. The benefits of preoperative RTH (e.g. limited area, lower dose, less risk of implantation of STS cells in the surgical wound, easier surgical intervention, lower rate of late complications) limit complications in wound healing [15]. The recommended dose for postoperative $\mathrm{RTH}$ is 60-66 Gy, and the treatment lasts 7-8 weeks. In conventional fractionated preoperative radiotherapy (1.8-2 Gy per day) the total dose is 50-50.4 Gy. The surgery is performed 4-8 weeks after the end of irradiation. The results of individual studies also indicate the possibility of using hypofractionated preoperative radiotherapy [16]. 


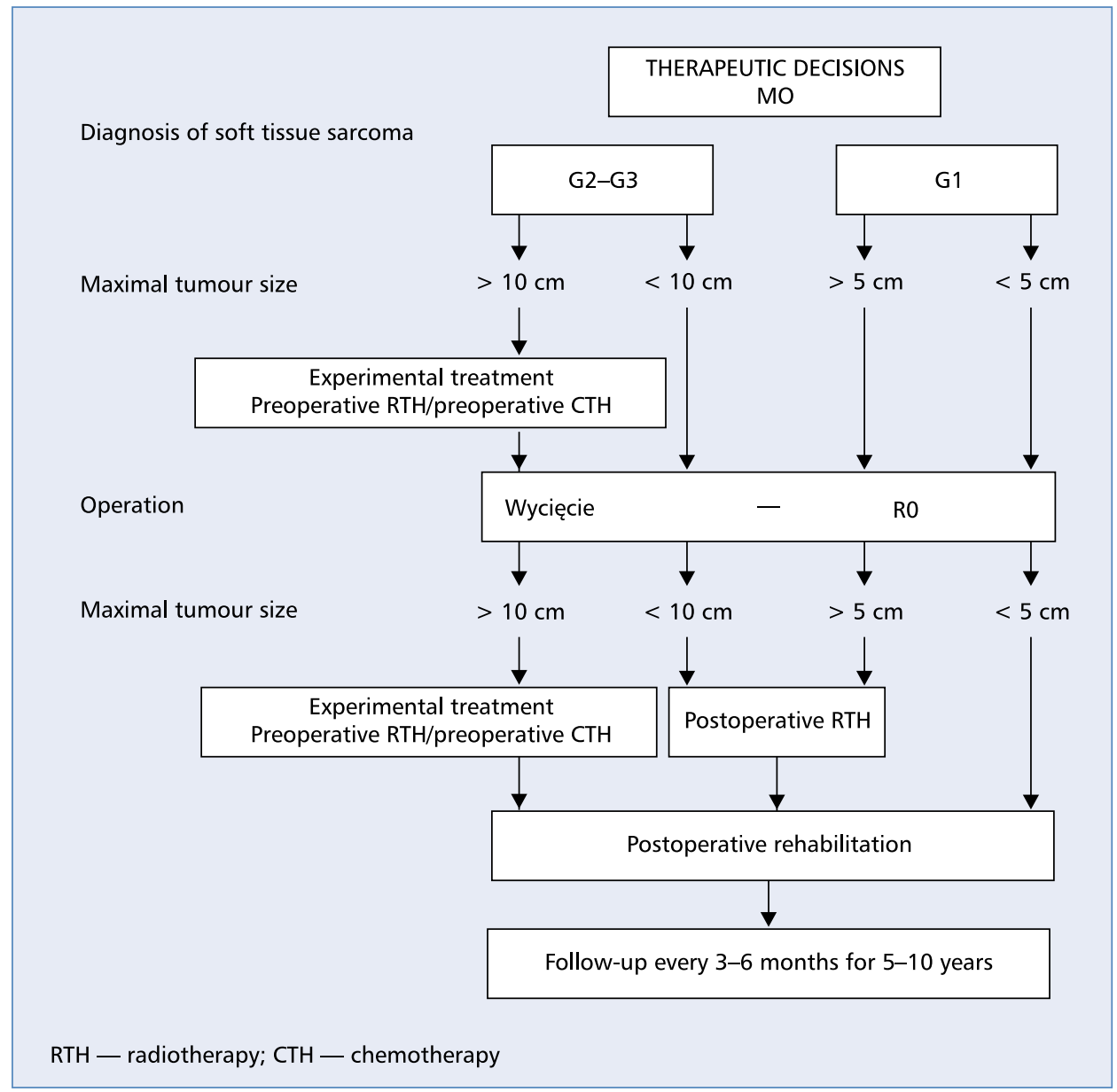

Figure 2. Scheme of treatment in localised resectable soft-tissue sarcomas

The indications for adjuvant RTH (conformal technique) in STS patients differ in following clinical situations [II, B]:

- after the resection of the primary lesion:

- high malignancy, size greater than $5 \mathrm{~cm}$,

- microscopic surgical margin below $1 \mathrm{~mm}$ (especially if suspected of spreading intraoperative by tumour damage during operation),

- all small-cell STS in combination with CTH,

- all STS located within the trunk and head and neck or after a previous operation (early — scars and operating are after a previous operation performed with the inappropriate margin; or late - resection of the recurrence confirmed microscopically).

\section{Adjuvant (preoperative or postoperative) chemotherapy}

Adjuvant CTH in adult patients with STS (except for small-cell STS and rhabdomyosarcoma) without disease spread is not a standard treatment. A meta-analysis of 14 clinical trials and 1568 STS patients undergoing postoperative $\mathrm{CTH}$ using doxorubicin showed improvement in disease-free survival by $10 \%$ (significant difference) and overall survival by approximately 6\% (non-significant difference) [17]. There is no clear evidence to improve the prognosis with the use of postoperative or postoperative $\mathrm{CTH}$ [18], but in individual STS with a diameter greater than $5 \mathrm{~cm}$ and a high degree of histological malignancy (G3), it is possible to decide on adjuvant treatment (especially in chemo-sensitive histological subtypes, e.g. synovial sarcoma [II, C] or CTH combination with hyperthermia [I, C]. In a recently published phase III randomised trial, it was demonstrated that in preoperative treatment of patients with high-risk STS located within the limb or trunk, chemotherapy adapted to the histological type of sarcoma should not be used because patients in the control group receiving three cycles of epirubicin and ifosfamide had a lower risk of recurrence or death, and the study was therefore discontinued. Consequently, patients with may be treated with a preoperative chemotherapy based on anthracycline with ifosfamide after careful 
multi-specialist evaluation of the potential benefit and the risk of adverse events [19].

Regional hyperthermia in combination with complementary CTH has been shown to improve local control and relapse-free survival (possible treatment [20]) in one randomised clinical trial (STS G2-3, sub-fascial, $>5 \mathrm{~cm}$ ). In the case of locally advanced limbic STS, one of the options is the preoperative use of isolated limb perfusion with cytostatics in hyperthermia [III, A] [21].

\section{Treatment of metastatic disease}

In the case of spread of the disease we can identify patients with:

- primarily surgical metastases limited to one organ (mainly lung), for which initial CTH, surgical metastatic excision, and subsequent CTH should be considered;

- more advanced and unresectable metastases for which treatment should be individualised $(\mathrm{CTH}$, RTH, symptomatic treatment).

The standard first-line CTH is anthracyclines (doxorubicin and epirubicin) $[\mathrm{I}, \mathrm{A}][22,23] \pm$ olaratumab (anti-PDGFR-alpha antibody) [I, B]. Ifosfamide, dacarbazine, gemcitabine, docetaxel, trabectedin, eribulin, and pazopanib are also active in the second line of treatment [24-26]. The results of clinical studies did not show a significant advantage of multidrug CTH over monotherapy, and administration of regimens (e.g. doxorubicin and dacarbazine) may be considered in selected histological types of high chemosensitivity and in cases in which the response to treatment depends on the possibility of surgical treatment of metastases. Some drugs may be used in specific STS types [II, B] (e.g. taxanes — angiosarcoma; gemcitabine \pm docetaxel - leiomyosarcoma; trabectedin — liposarcoma, especially myxoid liposarcoma or leiomyosarcoma [I, A] [25]; ifosfamide — synovial sarcoma; imatinib — dermatofibrosarcoma protuberans [27]; sunitinib — alveolar soft part sarcoma;
mTOR-inhibitors PEC-oma/lymphangioleiomyomatosis; crizotinib - inflammatory myofibroblastic tumour with the presence of $A L K$ rearrangement. The efficacy of trabectedin in the treatment of L-sarcoma after failure of at least one systemic treatment line has been confirmed in three randomised phase III trials [25, 28, 29] [I, A], and in phase II trials confirmed clinical benefit from maintenance therapy for progression of disease in patients who had disease control after six cycles of trabectedin [30]. Another drug for use in patients with advanced STS (other than liposarcoma) following failure of prior CTH is pazopanib - results of a randomised trial have shown improvement in progression-free survival of three months [26]. The promising results of randomised phase III and II controlled trials indicate the activity of eribulin in advanced liposarcoma [I, B] [31] and olaratumab in combination with doxorubicin in the first-line treatment of advanced STS [IB] [32]. Eribulin compared with dacarbazine in patients with advanced liposarcoma and leiomyosarcoma gave improvement in overall survival compared to dacarbazine (the median of $13.5 \mathrm{vs}$. 11.5 months). The benefit of therapy was seen primarily in liposarcoma patients. In the olaratumab study, the median overall survival was 26.5 months (95\% CI 20.9-31.7) for combination with doxorubicin (66 patients) and 14.7 months (95\% CI 9.2-17.1) for doxorubicin monotherapy (67 patients) (HR 0.46, 95\% CI 0.3-0.71, p = 0003), but these results need confirmation in the ongoing phase III study. In the United States, pre-registration of the EZH2 inhibitor tazemetostat was based on the preliminary results of a phase II study in adult patients with INI1-negative epithelioid sarcoma [II, C] [33].

Progress in systemic treatment of STS is related to the use of molecularly-targeted drugs that target specific intracellular metabolic pathways essential for etiopathogenesis and tumour progression. Some of these drugs have been registered in certain STS (Tab. 5).

Table 5. Molecular-targeted drugs that have registered indications in soft tissue sarcoma

\begin{tabular}{lll}
\hline Histological type of tumour & Drug & Molecular target \\
\hline GIST & Imatinib & KIT, PDGFRA \\
\hline GIST & Sunitinib & KIT, PDGFRA, VEGFR \\
\hline GIST & Regorafenib & KIT, PDGFRA, VEGFR \\
\hline DFSP & Imatinib & PDGFRB \\
\hline Liposarcoma & Trabectedin & ? NER/minor groove of the DNA helix \\
Leiomyosarcoma & & VEGFR, PDGFR \\
\hline The different histological types, except liposarcoma, mainly after & Pazopanib & \\
failure of prior therapy & & PDGFRA \\
\hline The different histological types in first-line therapy in combination & Olaratumab \\
with doxorubicin & &
\end{tabular}

GIST — gastrointestinal stromal tumour; DFSP — dermatofibrosarcoma protuberans 
The five-year survival rate is $35-75 \%$; the worst results are achieved in surgical departments with no experience in STS treatment, intermediate results (about $60 \%$ ) are published in multicentre clinical trial results, and the best come from multi-modality (unit) oncological centres using the full range of resources.

\section{Special clinical situations}

\section{Soft tissue sarcomas of the breast}

They account for about $1 \%$ of all recorded breast malignancies, including sporadic and previously irradiated tumours [34]. The most common types of histology are: malignant phyllodes tumour, angiosarcoma, and fibrosarcoma with varying degrees of histologic malignancy [35]. Angiosarcoma (usually with a high degree of malignancy) has a strong tendency towards local recurrence and is characterised by a worse clinical course, requiring a priori aggressive treatment with radiotherapy (chemotherapy) (high sensitivity to paclitaxel). The surgical treatment of choice should be simple amputation of the breast (especially in angiosarcoma) or radical resection without axillary lymphadenectomy; neoadjuvant radiotherapy (or possibly chemotherapy) is recommended according to the treatment regimen, as with other STS [1, 3].

\section{Uterine sarcomas}

The European Society for Medical Oncology distinguishes the following types of uterine sarcoma: leiomyosarcomas (LMS), endothelial stromal sarcomas (ESS), undifferentiated endometrial sarcomas, and pure heterologous sarcomas (most commonly rhabdomyosarcoma, chondrosarcoma) [3]. The clinical classification of TNM and FIGO (International Federation of Gynaecologists and Obstetricians) is presented in Table 6. The prognosis for low-grade malignant sarcoma (ESS) is good - the five-year survival is $80-100 \%$ even though $20-40 \%$ of patients have local recurrence of the disease after treatment [36, 37]. For patients with diagnosed LMS and high grade malignant sarcoma, prognosis is poor $[34,35]$ - three years of relapse-free survival is seen in only about $30 \%$ and is worse for postmenopausal women. In the case of distant recurrence, palliative chemotherapy is the primary option - the median overall survival in this group of patients is about 13 months. The only option that gives a chance for a cure in the case of late relapse is metastasectomy (mainly from the lungs). The standard local treatment for all these cancers is removal of the uterus from abdominal access [II, A] $[36,37]$. The importance of bilateral adnexectomy is not fully understood, although in stromal uterine sarcoma it is generally recommended because of the hormonal sensitivity of these tumours [III, A] [36, 37]. Ovarian retreatment in women under 35 years of age is recommended for tumours smaller than $3 \mathrm{~cm}$, but it is important to discuss the potential recurrence risk with the patient. In cases of LMS and non-differentiated sarcomas, both bilateral removal of adnexa (especially in premenopausal women) and pelvic lymphadenectomy did not show improvement in treatment outcome in the absence of macroscopic involvement of these tissues. In patients whose LMS was diagnosed postoperatively (e.g. after hysterectomy due to uterine fibroids), and in whom the procedure was microscopically radical (reoperation is not recommended in this case), imaging studies should be performed to exclude distant metastases because it is reported that up to $10 \%$ of patients with LMS have metastatic lesions in the lungs at diagnosis. In the case of locally advanced unresectable tumours, palliative radiotherapy should be considered [36, 37] [III, B]. Although there are reports of retrospective studies on the possible reduction of local recurrence using adjuvant radiotherapy in patients with uterine LMS, the impact on local recurrence and overall survival were not confirmed in the only randomised clinical trial [38]. Thus, complementary postoperative radiotherapy in this diagnosis is only a treatment option [II, C], and the decision to use postoperative radiotherapy may only affect a small proportion of patients with high risk of local recurrence, and it should be followed by careful multidisciplinary analysis of the case and an interview with the patient $[36,37]$. In the case of ESS there are reports suggesting improved survival in patients who have received postoperative hormone therapy (progesterone analogues - most commonly megestrol acetate or medroxyprogesterone), so it is recommended for patients in grades II-IV [III, B] $[36,37]$. As in all adult soft tissue sarcomas, the role of adjuvant chemotherapy in LMS uterus is not fully established [III, C]. Progesterone analogues, aromatase inhibitors, or LH-RH analogues (for premenopausal women) can be used as treatment for advanced uterine sarcoma. Oestrogen-based therapies and tamoxifen are contraindicated [II, B]. Treatment of advanced/metastatic leiomyosarcoma and non-differentiated sarcoma is similar to systemic treatment of other soft tissue sarcomas $[1,3,36,37]$.

\section{Fibromatosis (aggressive fibromatosis, desmoid-type fibromatosis)}

Fibromatosis is a disease with the clinical course of locally malignant STS, with no metastatic disease, characterised by local infiltration and the ability of local recurrence. The principle of the therapy is multi-specialist assessment and individualisation of treatment. In recent years the most common treatment is conservative treatment and active observation [III, B]. Results of active observation (wait-and-see) indicate that only about $20 \%$ of patients progress, and some patients experience not only stabilisation but also spontaneous regression after 
Table 6. Clinical classification of uterine sarcomas according to TNM (tumour/node/metastasis) and FIGO (Federation of Gynaecology and Obstetrics)

\begin{tabular}{|c|c|c|}
\hline \multicolumn{3}{|c|}{ Primary tumour (T) } \\
\hline TNM & FIGO & Definition \\
\hline \multicolumn{3}{|c|}{ Leiomyosarcoma and endometrial stromal sarcoma } \\
\hline $\mathrm{TX}$ & & The tumour cannot be assessed \\
\hline T0 & & No evidence of primary tumour \\
\hline $\mathrm{T} 1$ & 1 & Tumour limited to uterus \\
\hline T1a & IA & Tumour of the largest size $\leq 5 \mathrm{~cm}$ \\
\hline $\mathrm{T} 1 \mathrm{~b}$ & IB & Tumour in the largest dimension $>5 \mathrm{~cm}$ \\
\hline $\mathrm{T} 2$ & II & The tumour infiltrates tissue located outside the uterus but within the pelvis \\
\hline $\mathrm{T} 2 \mathrm{a}$ & IIA & The tumour infiltrates the appendix \\
\hline $\mathrm{T} 2 \mathrm{~b}$ & IIB & The tumour infiltrates the remaining pelvic tissues \\
\hline T3 & III & The tumour infiltrates the abdominal tissue \\
\hline T3a & IIIA & One place \\
\hline $\mathrm{T} 3 \mathrm{~b}$ & IIIB & More places \\
\hline T4 & IVA & The tumour invades the bladder or rectum \\
\hline \multicolumn{3}{|c|}{ Adenosarcoma } \\
\hline TX & & The tumour cannot be assessed \\
\hline T0 & & No evidence of primary tumour \\
\hline $\mathrm{T} 1$ & I & Tumour limited to uterus \\
\hline T1a & IA & Tumour limited to the endometrium/endocervix \\
\hline $\mathrm{T} 1 \mathrm{~b}$ & IB & The tumour infiltrates less than half the thickness of the myometrium \\
\hline T1c & IC & The tumour infiltrates more than half the thickness of the myometrium \\
\hline $\mathrm{T} 2$ & II & The tumour infiltrates tissue located outside the uterus but within the pelvis \\
\hline $\mathrm{T} 2 \mathrm{a}$ & IIA & The tumour infiltrates the adnexa \\
\hline $\mathrm{T} 2 \mathrm{~b}$ & IIB & The tumour infiltrates the remaining pelvic tissues \\
\hline T3 & III & The tumour infiltrates the abdominal tissue \\
\hline T3a & IIIA & One place \\
\hline T3b & IIIB & More places \\
\hline T4 & IVA & The tumour invades the bladder or rectum \\
\hline \multicolumn{3}{|c|}{ Regional lymph nodes (N) } \\
\hline TNM & FIGO & Definition \\
\hline \multicolumn{3}{|c|}{ Leiomyosarcoma and endometrial stromal sarcoma } \\
\hline NX & & Regional lymph nodes cannot be assessed \\
\hline NO & & No lymph node metastases \\
\hline $\mathrm{N} 1$ & IIIC & Lymph node metastases \\
\hline \multicolumn{3}{|c|}{ Adenosarcoma } \\
\hline NX & & Regional lymph nodes cannot be assessed \\
\hline NO & & No lymph node metastases \\
\hline N1 & IIIC & Lymph node metastases \\
\hline \multicolumn{3}{|c|}{ Metastases (M) } \\
\hline TNM & FIGO & Definition \\
\hline \multicolumn{3}{|c|}{ Leiomyosarcoma and endometrial stromal sarcoma } \\
\hline Mo & & No metastases \\
\hline M1 & & Metastasis (excluding adnexa, pelvic and abdominal cavity) \\
\hline \multicolumn{3}{|c|}{ Adenosarcoma } \\
\hline M0 & & No metastases \\
\hline M1 & & Metastasis (excluding adnexa, pelvic and abdominal cavity) \\
\hline
\end{tabular}


Table 6 cont. Clinical classification of uterine sarcomas according to TNM (tumour/node/metastasis) and FIGO (Federation of Gynaecology and Obstetrics)

\begin{tabular}{lcccc}
\hline Staging of uterine sarcomas & & & N0 & M0 \\
\hline IA & T1 & N0 & M0 & M0 \\
\hline IB & T1a & T1b & N0 & M0 \\
\hline IC & T1c & N0 & M0 & M0 \\
\hline II & T2 & N0 & M0 \\
\hline IIIA & T3a & T3b & Any N & M0 \\
\hline IVA & T4 & Any N & M1
\end{tabular}

about one year of follow-up [39, 40]. In progressive, symptomatic cases, surgery is performed within healthy tissues (sometimes in combination with postoperative radiotherapy) $[1,40]$ but remembering the principle that treatment should not lead to significant functional impairments. In the case of extensive lesions, or if the operation would involve severe disability, the use of radiotherapy alone is considered. The recommended dose of irradiation is 56 Gy in fractions of 2 Gy. The margin with which the lesion is irradiated is at least $5 \mathrm{~cm}$. The use of radiotherapy should be particularly limited at an early age and in the abdominal location (especially in coexistence with familial adenomatous polyposis) [40]. In non-operative cases, in the case of very extensive tumours, when surgery or radiotherapy is associated with severe disability, progressive treatment despite irradiation is followed by pharmacological treatment - most commonly starting with oral nonsteroidal anti-inflammatory drugs: indomethacin $100 \mathrm{mg} /$ day or sulindac $300 \mathrm{mg} /$ day or meloxicam $15 \mathrm{mg} /$ day (these drugs may also be used during active observation) [III, B]. Other non-cytotoxic drugs are hormonal medications: anti-oestrogens - tamoxifen at doses of 20 to $120 \mathrm{mg} /$ day or MPA (medroxyprogesterone acetate) $500 \mathrm{mg} /$ day $[1,40]$. In the absence of response to the above-mentioned treatment, classical cytotoxic chemotherapy is generally used with anthracyclines or vinblastine with methotrexate. There are also reports of the activity of multiple kinase inhibitors.

\section{Rehabilitation}

Rehabilitation should be started before surgery and implemented as early as possible after surgery and during follow-up, in some cases even for several years (due to late complications of RTH, e.g. contracture in joints). Within the framework of rehabilitation it is necessary to cooperate with specialists in the field of physical therapy, prosthetics, social and professional adaptation, and psychologists and psychiatrists.

\section{Follow-up after treatment}

The purpose of follow-up of patients after treatment of STS is early detection of possible recurrence of the disease, given the possibility of extending survival with less advanced metastatic disease or local recurrence (proposed standard recommendations of observation after treatment of STS - Tab. 7) [1, 3, 41].

Most recurrences (about $80 \%$ ) occur within three years of primary tumour treatment. STS relapse depends largely on the location of the primary tumour. In patients with STS with limb location the primary recurrences (metastases) are usually to the lungs, while in patients undergoing proper treatment local recurrences develop less frequently. Lymph node metastases may occur in some types of STS of the extremities and trunk (e.g. rhabdomyosarcoma, epithelioid sarcoma, clear cell sarcoma, or synovial sarcoma, and metastases in the abdominal organs are observed in the myxoid liposarcoma). In STS of retroperitoneal space or viscera, most commonly are observed local recurrences, and secondly liver metastases.

The results indicate that the effects of the treatment of adult patients with metastases in the lungs is improved in the case of a smaller number of metastatic lesions, indicating directly the importance of early detection during follow-up. Analysis of the importance of regular follow-up examinations after STS treatment show that chest X-ray allows more than $60 \%$ of lung metastases to be detected before the onset of clinical symptoms - chest X-ray is sufficient in routine chest control studies and there is no need for chest CT. Detection or suspicion of a nodule in the chest X-ray is an indication to perform a CT to confirm the metastasis and to evaluate the number and location of lung nodules, pleural imaging, and mediastinal, lumbar, and mediastinal lymph nodes. Periodic chest CT examination should be performed only in patients with STS with a very high risk of spread of the disease and metastases after resection. After five years of follow-up, chest X-rays should be performed at 12-month intervals. 
Table 7. Scheme of follow-up in patients with soft tissue sarcomas

\begin{tabular}{|c|c|c|}
\hline Tumour stage & Type of follow-up & $\begin{array}{l}\text { The frequency of } \\
\text { follow-up }\end{array}$ \\
\hline $\begin{array}{l}\text { After radical treatment of } \\
\text { sarcoma in stages IA-IB (low } \\
\text { histological grade G1) }\end{array}$ & $\begin{array}{l}\text { Physical examination every 3-6 months for the first 2-3 years, then once } \\
\text { a year. Chest X-ray every 6-12 months, CT only in case of suspicion of } \\
\text { lesions in RTG. Consider local evaluation after resection } 6 \text { months after } \\
\text { surgery with imaging (MR, CT, or USG); regular checks every } 6 \text { months } \\
\text { (for the first 2-3 years, then once a year) with contrast-enhanced CT } \\
\text { only for retroperitoneal and intraperitoneal space sarcoma, in other } \\
\text { cases imaging only with clinical suspicion of recurrence. The need for } \\
\text { education of the patient in the field of self-control }\end{array}$ & $\begin{array}{l}\text { Every } 3-6 \text { months during } \\
\text { the first } 2-3 \text { years, } \\
\text { then every } 12 \text { months } \\
\text { (> } 10 \text { years, only in } \\
\text { cases undergoing } \\
\text { perioperative RTH) }\end{array}$ \\
\hline $\begin{array}{l}\text { After radical treatment } \\
\text { of sarcoma in stages II-III } \\
\text { (with higher histological } \\
\text { grade G2/G3 or after lymph } \\
\text { node metastasis) }\end{array}$ & $\begin{array}{l}\text { Symptoms and physical examination, especially of the scar after sarcoma } \\
\text { resection and regional lymph nodes. RTG or CT of the chest. Initial site } \\
\text { evaluation 3-6 months after surgery (MR, CT, or USG) may be used to } \\
\text { control the site of surgery. Ultrasonography may be used; other tests } \\
\text { should not be performed more than once a year. Regular check-ups } \\
\text { every } 6 \text { months (for the first 2-3 years, then once a year) with CT and } \\
\text { contrast pelvic examinations only in retroperitoneal and intraperitoneal } \\
\text { space sarcoma, due to the difficulty in assessing the location of the } \\
\text { tumour. The need to educate the patient towards self-control }\end{array}$ & $\begin{array}{l}\text { Every 3-4 months for the } \\
\text { first 2-3 years, then every } \\
6 \text { months to } 5 \text { years after } \\
\text { radical treatment, then } \\
\text { once a year }\end{array}$ \\
\hline $\begin{array}{l}\text { After treatment of distant } \\
\text { metastases (grade IV) }\end{array}$ & $\begin{array}{l}\text { Evaluation in imaging studies based on the location of measurable } \\
\text { metastatic foci }\end{array}$ & $\begin{array}{l}\text { Individual follow-up } \\
\text { schedule for every patient }\end{array}$ \\
\hline
\end{tabular}

Follow-up to detect local recurrences primarily should include a careful examination, with the possible addition of scar ultrasound (USG) in the case of lesions easily accessible on the limbs or trunk. The patient should also be advised on the possible recurrence of symptoms, as the self-control of scar tissue after primary excision, made by the patient, often leads to finding of relapse of the disease outside the control visit schedule.

Some experts recommend that for patients with high-grade STS located in the limb, the original location of the tumour should be assessed with ultrasound or MRI (routine use of these tests is not justified on the basis of analyses of efficacy against costs). In the case of STS originally located in the retroperitoneal, intraperitoneal, or inguinal area, imaging methods (CT or MR) are effective. Local recurrences in the retroperitoneal or intraperitoneal space are more frequent than in the limb or abdominal and thoracic areas (these locations are inaccessible in the physical examination). Less aggressive control regimens are warranted, especially in the case of second retroperitoneal recurrence (no evidence of survival improvement in the event of early relapse).

In experienced oncology centres, routine check-ups are performed every 3-4 months for the first 2-3 years after treatment and then every six months for the next two years, and later once a year. The risk of recurrence of the disease depends on the degree of histological malignancy and the size of the STS, if the primary treatment was radical, and the time from the initial treatment. It is known that in low-grade STS and particle size smaller than $5 \mathrm{~cm}$ the risk of relapse after radical treatment is very low. In the case of easy accessibility of postoperative scar, when it is possible to assess by physical examination, there is no need to perform any additional imaging studies, and it should be considered only to perform chest X-ray in two planes every 6-12 months for the first three years, and then a check every year. On the other hand, in cases of high-grade malignancy, the risk of metastases to the lungs and local recurrence is significant, it is necessary to perform cyclic chest X-ray, and - in addition to careful examination of the subject - it may be justified to direct the patient to the imaging examination of the area after the primary tumour. None of the laboratory tests used thus far lead to effective detection of STS recurrence. In the case of locations that are difficult to access in the physical examination (retroperitoneal and intraperitoneal site), periodic assessment for disease recurrence should be made by means of imaging studies (choice - CT with contrast). The value of positron emission tomography (PET) is not yet established. It is also important to inform the patient that even 10 years after primary STS treatment, there may be late cancer recurrence or the development of tumours induced by radiotherapy during combination therapy. 


\section{Gastrointestinal stromal tumours}

GISTs are a separate group of the most common mesenchymal tumours of the gastrointestinal tract, probably derived from precursors of Cajal "pacemaker" cells (responsible for peristaltic intestinal movement). The initiating factor for malignancy is an activating mutation in the genes encoding membrane receptor KIT or PDGFRA, overexpression of which is highly specific for GIST, and overexpression of membrane receptor KIT can subsequently be detected by immunohistochemistry (IHC) expression of CD117 in histological sections, which is the main criterion in its microscopic diagnosis and indications for the treatment with small molecule tyrosine kinase inhibitors [1, 42, 43]. Clinically, GIST represents a broad spectrum of lesions - from small, benign tumours found accidentally during endoscopic or surgical procedures, to very aggressive tumours leading to massive metastases. These cancers, thanks to advances in the diagnosis of pathological molecules, are widely recognised only after several years. The basic and valid principle should be the treatment of GIST inoperative and/or metastatic GISTs within multidisciplinary teams experienced in the treatment of STS. Treatment should be limited to a few specialised centres in Poland, which justifies a small number of patients eligible for tyrosine kinase inhibitors therapy (about 200 per year).

\section{Epidemiology}

Epidemiological findings on GIST of the gastrointestinal tract are rarely published. A retrospective population-based study in Sweden showed that the incidence of GIST (including low-risk and aggressive forms) is $15-16$ cases/year/million - in Poland this would correspond to more than 600 new cases annually. In the United States the number of metastatic/non-operative GISTs is estimated at over 1000 new cases per year (3-4 cases per 1 million inhabitants); this would mean that 150-190 new metastatic GIST cases can be expected in Poland. The GIST Registry Report (gist@coi.waw.pl; http://gist.coi.pl) indicates that these are now the most commonly diagnosed malignant mesenchymal tumours of the gastrointestinal tract.

The majority of patients $(75 \%)$ at the time of diagnosis are over 50 years of age (median: 55-65 years), but GIST can occur at any age.

Approximately $90 \%$ of GISTs have primary location in the gastrointestinal tract, much more rarely in the retroperitoneal space, or they cannot be established due to multifocal intraperitoneal spread $(<10 \%)$. Population studies show that GISTs are most common in the stomach (40-70\%), followed by the small intestine (20-50\%), and less often in the large intestine (about $5 \%$ ) or oesophagus (less than $5 \%$ ).

\section{Diagnostics}

\section{Symptoms and physical examination}

GIST clinical symptoms are non-specific and include abdominal pain, obstruction or chronic gastrointestinal bleeding, and perceptible abdominal tumours (sometimes acute "abdominal symptoms"). Minor lesions remain asymptomatic and can be detected accidentally. Some (about 40\%) GIST patients are operated in gynaecological departments, with initial diagnosis of ovarian cancer.

GIST relapses after primary surgery are mainly in the abdominal cavity. In more than half of the cases there are metastases in the liver (isolated or coexisting with intraperitoneal spread). Isolated intraperitoneal spread is found in about $30-40 \%$ of patients. Isolated local recurrences are rare.

\section{Imaging studies}

CT scan of the abdomen with intravenous and oral contrast is the preferred imaging modality used in GIST for staging and planning of the surgical procedures, including laparotomy and biopsy (R2). In the case of GIST located in the rectum, diagnostic MR may be used alternatively, and in case of GIST suspicion, endoscopic ultrasonography is helpful.

\section{Pathological assessment}

In the case of primary GIST suspicion, with appropriate technical conditions, a needle biopsy under endoscopic ultrasound may be performed - a core-needle biopsy or an open biopsy by laparotomy (cut or incision); some of the fresh material should be freeze-free (about $-80^{\circ} \mathrm{C}$ ) for possible molecular testing. In the case of minor lesions $(\leq 2 \mathrm{~cm})$ of the upper gastrointestinal tract, endoscopic examination may be the only procedure, and any possible removal of the lesion may be reserved for cases of enlargement during observation [IV, C].

GISTs are characterised by microscopic epithelioid or spindle epithelial cells and mixed (exceptionally: pleomorphic). All mutations in the KIT or PDGFRA genes are receptor activating, and in most cases GIST expresses the CD117 antigen (a protein epitope produced by the KIT gene) and/or DOG1, which can be detected by immunohistochemistry. In a few cases (less than 5\%) CD117 expression is not observed in the presence of mutations in the KIT or PDGFRA genes. The term "benign" GIST is not used. In CD117-negative tumours, the presence of mutations in the KIT and $P D G F R A$ genes is required along with re-consultation at a pathology facility experienced in GIST diagnosis. The test material may be tumour tissue from a paraffin block or (better) frozen tissue.

Mutations in the KIT and PDGFRA genes that encode membrane receptors with tyrosine kinase activity 


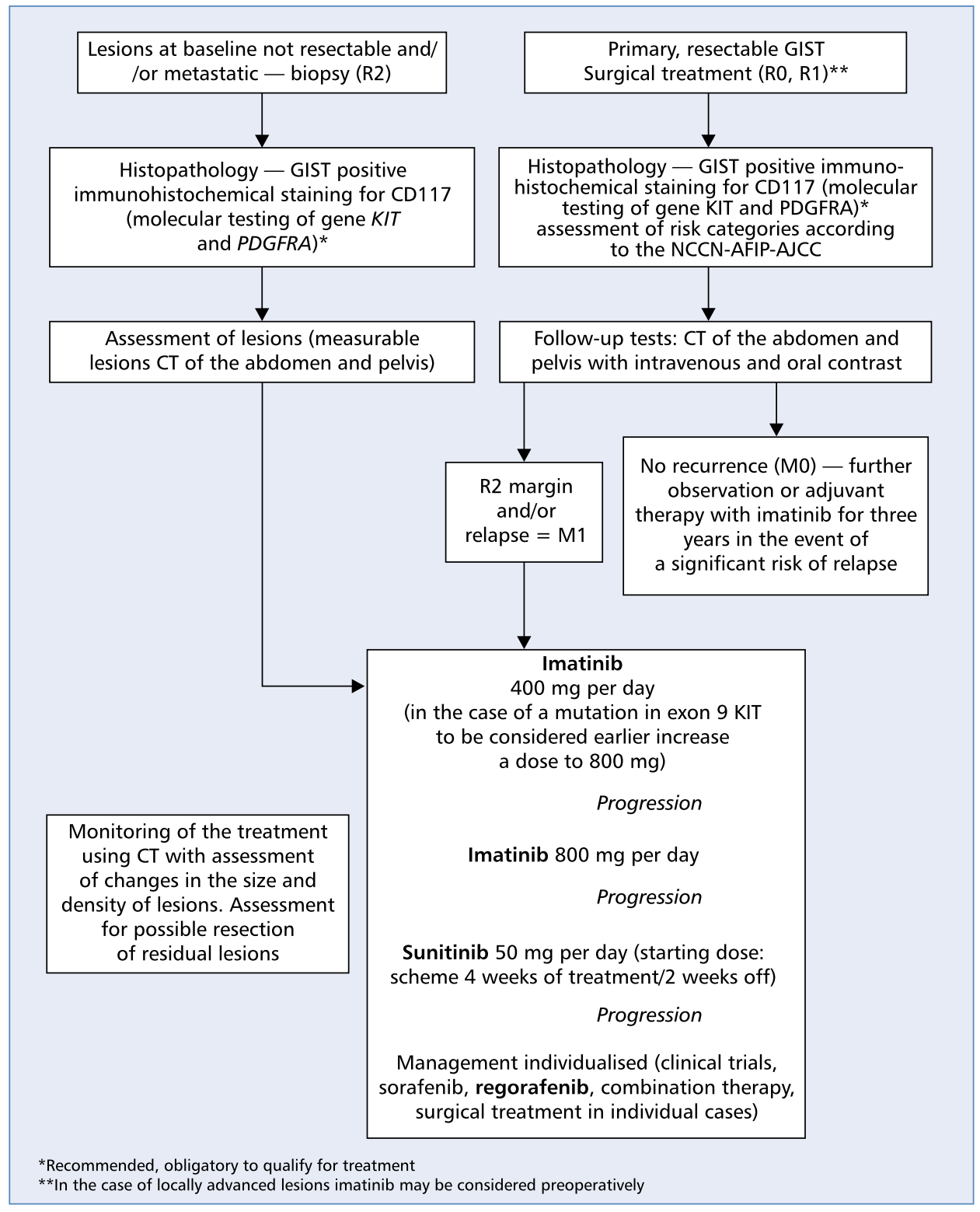

Figure 3. Treatment algorithm in gastrointestinal stromal tumours (GIST)

are mutually exclusive (i.e. not present in both genes simultaneously) and activated (i.e. receptors become metabolically active without the need to bind to ligand). The GIST mutations are most commonly observed in KIT proto-oncogene - most (about 70\%) occur in exon 11 , rarely in exon $9(6-8 \%)$, and occasionally in exon 13 and 17. In many GISTs where there is no KIT mutation there are mutations in the PDGFRA gene (mainly exon 18 and, less often, exon 11). The presence of the mutated KIT or PDGFRA gene in GIST is important in predicting the response to imatinib - in each case of GIST diagnosis and after initiation of treatment, it is recommended that the material (may be paraffin blocks) is sent for molecular assay [IV, B].

\section{Treatment}

The principles of diagnostic and therapeutic procedures in GIST are presented in Figure 3. It is recommended that patients are treated by multidisciplinary teams experienced in GIST therapy, and that new cases of this type are included in prospective clinical trials.

\section{Primary surgical treatment}

The most effective method of treatment for GIST is radical surgical treatment with the intention of cure (35-65\% of five-year survival without relapse), which consists of open resection of the stomach, small intestine, intestine fat, or intraperitoneal/retroperitoneal 
injection within the limits of macroscopically healthy tissue (Tab. 8).

In the case of the gastric GIST, most often local excision of the tumour with a fragment of the wall of the stomach (wedge resection) is performed, less frequently partial or total resection (extent of gastric resection is not relevant for the risk of recurrence of cancer), and subsequent reoperations of recurrent GIST do not lead to cure. In other sites, segmental resection of the small intestine or hemicolectomy are performed. Unlike in carcinomas of the digestive system there is no need to remove the loco-regional lymphatic system because lymph node metastases occur sporadically in GIST $(<3 \%$ of patients). In the case of R1 resection (microscopically non-radical resection), re-operation may be considered as long as it is possible to determine the location of the primary tumour and the surgery is not connected with serious consequences for the functioning of the

Table 8. Principles of primary surgical treatment of gastrointestinal stromal tumours (GIST)

Resection of the tumour within the healthy tissues (the

margin of 1-2 cm; preferred organ-sparing operations, wedge

excisions )

Avoiding intraoperative tumour rupture

Usually lymphadenectomy is not necessary

The role of laparoscopy is uncertain (contraindicated for

larger tumours)

Precise evaluation for metastatic disease (especially

exploration of the peritoneal recesses)

Consideration of the initial treatment with imatinib instead of

mutilating surgery in locally advanced cases

Securing tissue (freezing) for molecular tests alimentary tract (in which case, only observation after surgery is recommended). It is not recommended that laparoscopic R1 resection in primary GIST of larger sizes be performed. Surgical techniques with lower invasiveness (e.g. laparoscopic resections and endoscopic techniques) will probably play an increasingly important role in the removal of small gastric GIST. The method of local excision through the anus in the future may be used in the removal of small GIST with low risk of aggressiveness and rectal location. During the operation it is particularly important to avoid damage or rupture of the tumour because it is considered a negative prognostic factor.

In patients with locally advanced GIST (borderline operability) extensive multiorgan resections should be avoided (e.g. abdominal-pectoral amputation or pancreatoduodenectomy), and reoperations of relapse are particularly inadvisable (GIST diagnosis is already known after the first surgery). In these situations, treatment with imatinib should be considered before surgery (daily dose $400 \mathrm{mg}$ ) with closely controlled CT performed every two months, with the possibility of surgical procedures in cases of maximum response to imatinib, usually after 6-12 months of therapy [II, A] [44].

\section{Assessment of the risk of relapse and the principles of observation after primary therapy}

For each patient after primary GIST surgery and receiving a definitive histopathological result, the risk of recurrence should be assessed according to the National Comprehensive Cancer Network (NCCN-AFIP-AJCC) classification, which is the basis for the classification of staging AJCC 2010 (Tab. 9) [45]. The most important risk factors for recurrence after primary excision are the value of the mitotic index, the size and location of the tumour, and the state of the surgical margins (es-

Table 9. TNM staging of gastrointestinal stromal tumours (GIST)

GIST of the stomach/omentum Intestine GIST

(+ mesentery, oesophagus, intraperitoneal)

\begin{tabular}{|c|c|c|c|c|c|c|c|c|c|}
\hline Stage & $\mathbf{T}$ & $\mathbf{N}$ & $\mathbf{M}$ & IM & Stage & $T$ & $\mathbf{N}$ & M & IM \\
\hline IA & $\mathrm{T} 1$ or $\mathrm{T} 2$ & No & Mo & Low & 1 & $\mathrm{~T} 1$ or $\mathrm{T} 2$ & No & M0 & Low \\
\hline IB & T3 & No & Mo & Low & II & T3 & No & M0 & Low \\
\hline \multirow[b]{3}{*}{ II } & $\mathrm{T} 1$ & NO & MO & High & \multirow{2}{*}{ IIIA } & $\mathrm{T} 1$ & NO & M0 & High \\
\hline & $\mathrm{T} 2$ & NO & MO & High & & T4 & NO & M0 & Low \\
\hline & T4 & NO & Mo & Low & \multirow{3}{*}{ IIIB } & T2 & NO & Mo & High \\
\hline IIIA & T3 & No & Mo & High & & T3 & No & M0 & High \\
\hline IIIB & T4 & NO & Mo & High & & T4 & & & High \\
\hline \multirow[t]{2}{*}{ IV } & Any $T$ & N1 & Mo & Any & \multirow{2}{*}{ IV } & Any $T$ & N1 & Mo & Any \\
\hline & Any T & Any N & M1 & Any & & Any T & Any N & M1 & Any \\
\hline
\end{tabular}

$\mathrm{T}$ - tumour size (T1 - tumour with maximum size $2 \mathrm{~cm}$; T2 - tumour with maximum size $>2$ and $\leq 5 \mathrm{~cm} ; \mathrm{T} 3-$ maximum tumour size $>5$ and $\leq 10 \mathrm{~cm}$; T4 - tumour with maximum size $>10 \mathrm{~cm}$ ); IM - mitotic index (number of mitotic for $50 \mathrm{HPF}$ : low $\leq 5$ or high $>5$ ); $\mathrm{N}-$ regional lymph nodes (N0 - absence of metastasis; N1 - metastases); M - distant metastasis (M0 - absence of metastases; M1 - metastases); TNM — tumour-node-metastasis 
pecially intraoperative tumour rupture) [46] [I, A]. In GIST derived from the stomach, the prognosis is better than for localisation in the small or thick intestine. The patient should be informed of the possibility of relapse after a long period of excision of the primary tumour. Patients from groups with high and intermediate degrees of aggressiveness, when they are not qualified for adjuvant therapy, should be closely monitored by means of a CT scan of the abdomen and pelvis contrast every 3-4 months for the first two years after resection of the primary tumour, then every six months to five years after the initial surgery, and once a year after five years. The same monitoring interval applies to patients after completion of adjuvant treatment. In the case of low-aggression GIST resections, control tests can be performed once a year (Tab. 10).

\section{Adjuvant therapy}

Adjuvant treatment with imatinib for three years in patients with high risk of recurrence increases relapse-free survival and overall survival compared with a schema of one-year therapy [SSGXVIII study] [II, A] [47]. The results of the earlier ACOSOG Z9001 trial, wherein the adjuvant imatinib was used for a year, led to the registration of imatinib in post-operative treatment of GIST with a significant risk of recurrence. In light of current knowledge, patients with very low or low risk of recurrence should not receive adjuvant treatment with imatinib. Adjuvant treatment in a group with a high risk of recurrence after resection of the primary tumour should last for three years. At the same time, at patient qualification for the adjuvant treatment, it is mandatory to assess the mutation status of GIST - the use of adjuvant treatment with imatinib in GIST genotypes with low sensitivity to imatinib (PDGFRA D842V or wild-type) remains questionable.

The greatest benefit of adjuvant therapy is seen in patients at highest risk of relapse $(>5$ mitoses/50 HPF and/or tumour size $>5 \mathrm{~cm}$, location of the primary tumour in other parts of the gastrointestinal tract than the stomach, resection within microscopically confirmed infiltrated margins surgical - R1, or rupture of the tumour during surgery).

\section{Treatment in an advanced stage}

Advanced GIST (unresectable or pre-metastatic tumour) are resistant to conventional chemotherapy. The value of radiotherapy has not been finally determined, although the effects of palliative radiotherapy on locally unresectable lesions (pelvis) or bone metastases are encouraging. Currently, standard treatment for patients with unresectable lesions, recurrent or metastatic, is imatinib [I, A].

Current I-III prospective clinical trials for imatinib-inoperable or disseminated GIST have shown that complete responses are rarely observed (about 5-7\%),
Table 10. Eligibility criteria for imatinib therapy for patients with advanced gastrointestinal stromal tumours (GIST)

Pathological diagnosis of GIST

Positive immunohistochemical result for CD117

Non-resectable lesions and/or metastasis in the CT or MRI

Lesions measurable in CT imaging (MRI)

Performance status $0-3$ according to WHO

Preserved absorption from the gastrointestinal tract

Adequate renal and liver function

Obtaining written consent of the patient

most often with partial remission (about 50\%) and stabilisation of the disease (about $36 \%$ ) and sporadically primary and early resistance (about $10 \%$ ), and the number of metastases is not relevant for the likelihood of achieving response [48, 49]. Longer-term use of imatinib in advanced GIST increases the percentage of partial responses in patients with stabilisation seen in the first months of treatment but is associated with a higher rate of progression. The long-term outcome of the phase II study (observation $>4$ years) showed that the median total survival in advanced GIST patients was about five years, which is about four times longer than the historical data (median survival: 12-15 months). Similar results were published by the Polish multicentre group within the framework of the GIST Clinical Registry. It is now widely accepted that treatment with imatinib should be continued until tumour progression (even for several years) because discontinuation of therapy may result in rapid progression of the disease.

Toxicity of treatment occurs in the majority of patients, but generally has the severity of grade I or II according to the scale of the World Health Organisation - the most common are: anaemia, oedema, especially periorbital, weakness, diarrhoea, nausea, granulocytopaenia, muscle cramps, and skin rash. Some of the symptoms may resolve spontaneously and without interruption of treatment; a significant degree of anaemia, with the need to supplement the deficiencies of blood is rare ( $<15 \%$ of patients). Before initiation of therapy morphology and biochemical parameters of blood should be tested and performance status according to the WHO evaluated. During treatment it is necessary to monitor the patient for toxicity, especially in the initial period of treatment (every two weeks for the first month, every month for the next six months, and then, in the case of obtaining responses and good tolerability, every three months). The patient should systematically take imatinib at the recommended daily dose. During the treatment, interactions with many other drugs (especially metabolised by cytochromes liver) should be taken into account. 
Table 11. Treatment of advanced gastrointestinal stromal tumour (GIST) after progression during imatinib therapy

In the case of early resistance, verification of diagnosis (including molecular diagnostics)

Increasing the daily dose of imatinib $800 \mathrm{mg}$ (at least stabilisation of the disease in approx. $30 \%$ of patients) and a check of other

medications taken by the patient (e.g. acting on the enzyme system in the liver and changing the concentrations of imatinib in the blood)

In the case of limited progression, it is necessary to consider surgery or ablative approach (continue treatment with imatinib for the control of most of the lesions)

The use of sunitinib malate in second-line treatment

In case of further progression regorafenib (optional sorafenib - off label use) in the third line and enrolment of patients to

prospective clinical trials on new drugs

Criteria for the qualification of GIST patients for imatinib include relapses following surgery in the form of liver metastases and/or intraperitoneal dissection, and unresectable primary and/or local recurrences (Tab. 10).

Treatment is started at a dose of $400 \mathrm{mg}$ imatinib administered orally at a single dose per day. It is now recommended to increase the dose to $800 \mathrm{mg}$ $(2 \times 400 \mathrm{mg} / \mathrm{d}$.) in case of progression. In cases of III-IV toxicity, the dose should be reduced to $600 \mathrm{mg}$ $(2 \times 300 \mathrm{mg} / \mathrm{d})$. There are studies that indicate the need to initiate treatment with a daily dose of $800 \mathrm{mg}$ in the presence of a specific mutation in exon 9 of the KIT gene for better progression-free survival.

The efficacy of imatinib is monitored solely on the basis of intravenous and oral contrast-enhanced CT (ultrasound is not useful). The first KT study should be carried out a few days before the start of treatment, then every two months for the first six months of therapy, and then every 3-4 months. In some patients, clinical benefit is delayed (median time to treatment response: four months), and the first complete assessment of response to therapy should be performed after four months, and at least two further CTs. The primary parameters evaluated are the size of tumour changes according to the criteria for the response of tumours - Evaluation Criteria in Solid Tumours (RECIST) - the sum of the longest dimensions of measurable tumours - and the determination of the density of lesions (so-called Choi criteria). The response should be assessed very carefully, which is particularly important in differentiating between stabilisation (inhibition of progression) and actual progression because patients with stable disease as assessed by conventional RECIST criteria benefit significantly from treatment (an effect similar to that seen in patients with partial response to therapy). Caution is advised due to the fact that in the early stages of treatment the reduction of the density of tumour lesions (e.g. multiple metastases in the liver) may result in a false image of "new" lesions or an apparent increase in the prevalence of lesions, which does not correspond to the progression of the disease. The fastest response to the therapy assessment can be obtained by PET-CT.
During the treatment with imatinib some patients experience disease progression associated with resistance to the drug (Tab. 11). A small proportion of patients (10-15\%) well qualified for the treatment (GIST $\mathrm{CD} 117+)$ show primary and early resistance during the initial six months of treatment. In patients responding to the treatment, along with extending the treatment duration, secondary (acquired) resistance to imatinib can occur. It is estimated that during 2-3 years of treatment with imatinib $40-50 \%$ of patients show evidence of progressive disease. In imaging studies a limited form of progression can be present (e.g. the appearance of 1-2 lesions with maintained regression of the other metastases or the appearance of a growing nodule within necrotic modified metastasis — the so-called "nodule within the mass" sign). Generally, however, the features of multifocal progression are observed. It was found that different mechanisms probably accompany primary and secondary resistance, which occurs during treatment with imatinib. The most common secondary resistance is a result of the acquisition of additional mutation or mutations in KIT or PDGFRA, which lead to changes in receptor conformation and the inability to bind to imatinib. Taking into account the primary molecular characterisation of GIST, the best response to imatinib is observed in cases of the most common mutation in exon 11 (encoding the intracellular membrane area at a transmembrane receptor KIT), and much worse results in the case of mutation in exon 9 or absence of mutations in the KIT gene (sometimes related to the presence of mutations in PDGFR, especially D842V) [50] [I, A].

In cases of progression after increasing imatinib to a maximum dose of $800 \mathrm{mg}$ [II, A], the use of second-line tyrosine kinase inhibitors should be considered. The use of other inhibitors, acting on different points in the metabolic pathway than those associated with exon 11 KIT mutation, can help overcome resistance to imatinib. Currently, the only approved drug in the second line with resistance to imatinib or intolerance to treatment is sunitinib, which is a multikinase tyrosine receptor inhibitor working on KIT, PDGFR, vascular endothelial growth factor (VEGFR), and FLT3. Available data indicate the possibility of 
Table 12. Recommended follow-up in patients with soft tissue sarcomas (excluding gastrointestinal stromal tumours - GIST)

\begin{tabular}{|c|c|c|}
\hline Stages of treatment & Type of examination & Frequency of performed tests \\
\hline $\begin{array}{l}\text { After radical treatment of } \\
\text { GIST with low and very } \\
\text { low risk of recurrence of } \\
\text { the disease (stage I) }\end{array}$ & $\begin{array}{l}\text { There are no absolute indications for regular follow-up; } \\
\text { examination by ultrasound or a CT of the abdomen } \\
\text { and pelvis once a year may be considered. The patient } \\
\text { must be informed about the existing low risk of relapse } \\
\text { a long time after treatment }\end{array}$ & Annually \\
\hline $\begin{array}{l}\text { After radical treatment of } \\
\text { GIST intermediate risk of } \\
\text { recurrence (stage II) }\end{array}$ & $\begin{array}{l}\text { Examination and symptoms, standard CT of the } \\
\text { abdomen and pelvis with contrast; other tests } \\
\text { individualised and depending e.g. on the location of the } \\
\text { primary tumour (e.g. MRI of the pelvis for rectal GIST, } \\
\text { CT of chest in oesophageal GIST) }\end{array}$ & $\begin{array}{l}\text { Every } 3-6 \text { months during the first } 2-3 \text { years, } \\
\text { every } 6-12 \text { months up to } 5 \text { years after the } \\
\text { initial surgery, and once a year after } 5 \text { years }\end{array}$ \\
\hline $\begin{array}{l}\text { After radical treatment of } \\
\text { GIST with a high risk of } \\
\text { recurrence (grade III) }\end{array}$ & $\begin{array}{l}\text { Examination and symptoms, standard CT of the } \\
\text { abdomen and pelvis with contrast; other tests } \\
\text { individualised and depending e.g. on the location of the } \\
\text { primary tumour (e.g. MRI of the pelvis for rectal GIST, } \\
\text { CT of chest in oesophageal GIST) }\end{array}$ & $\begin{array}{l}\text { Every } 3-4 \text { months for the first } 2-3 \text { years, } \\
\text { every } 6 \text { months up to } 5 \text { years after the } \\
\text { initial surgery, and once a year after } 5 \text { years } \\
\text { (in the case of adjuvant treatment with } \\
\text { imatinib, such a scheme is valid from } \\
\text { completion of the adjuvant treatment) }\end{array}$ \\
\hline $\begin{array}{l}\text { After the treatment } \\
\text { of distant metastases } \\
\text { (stage IV) }\end{array}$ & $\begin{array}{l}\text { Evaluation in imaging studies, depending on the } \\
\text { location of measurable metastases - usually CT or } \\
\text { a MRI of the abdomen and pelvis }\end{array}$ & $\begin{array}{l}\text { Program of control visits for each individual } \\
\text { patient; during treatment with tyrosine } \\
\text { kinase inhibitors follow-up is recommended } \\
\text { every } 2-3 \text { months }\end{array}$ \\
\hline
\end{tabular}

long-term response in approximately $40 \%$ of imatinib-resistant GIST patients, especially in the presence of primary mutation in exon 9 or absence of KIT gene mutations (e.g. GIST in children). The median time to progression of GIST patients treated with sunitinib is $6-8$ months [I, A] [51, 52]. In the case of sunitinib, treatment should be initiated with a daily dose of $50 \mathrm{mg}$ in a six-week regimen (four weeks of active treatment and two weeks' pause). In the case of the occurrence of toxicity, the daily dose of sunitinib can be reduced to 37.5 or $25 \mathrm{mg}$ and there can be extended breaks in the regimen. An increasingly widely accepted alternative is a continuous dosing regimen ( $37.5 \mathrm{mg}$ every day without interruption), which seems more justified in the case of tyrosine kinase inhibitors. The side effects in grade III-IV toxicity are more frequent than in the case of treatment with imatinib, and include mainly the occurrence of hand-foot syndrome, fatigue, neutropaenia, thrombocytopaenia, diarrhoea, nausea, mucositis, hypertension, and hypothyroidism.

Prolongation of progression-free survival with regorafenib in patients with GIST-resistant GIST was demonstrated in a prospective, randomised, placebo-controlled trial after failure of imatinib and sunitinib and is now a registered option within the third line of proceedings [I, A] [53]. In Poland it is now possible to treat patients after progression on imatinib and sunitinib using sorafenib outside the registration indications [II, A] [54]. In the case of further progression, it is recommended that the patient be included in clinical trials with new medications (e.g. BLU-285, DCC-2618, crenolanib), which in phase I studies has shown promising activity also in the case of occurrence of PDGFRA D842V mutation.

In the case of symptomatic lesions or rare limited progression of the disease, local treatment may be considered (radiofrequency ablation, surgical resection, chemoembolisation of the hepatic artery branch). In rare cases of bone metastases, palliative RTH should be considered. In selected cases the resumption of imatinib treatment at a daily dose of $400 \mathrm{mg}$ can also be reassessed, which can significantly slow the progression of the disease (some of the lesions remain susceptible to imatinib treatment).

A small proportion of total remissions observed in imaging studies during imatinib therapy, while increasing the number of patients with progression due to secondary mutations and clinically late resistance, lead to individualised use of surgical methods to improve imatinib treatment outcomes. Surgical treatment with tyrosine kinase inhibitors should be planned in patients with initially pronounced partial response and subsequent stabilisation of two consecutive CT tests (i.e. 4-6 months) and based on the possibility of resection of lesions [III, C] [55]. At the same time, it is necessary to continue imatinib and/or sunitinib treatment after residual (including radical) resection. Surgical treatment should not be used in cases of multifocal GIST progression with imatinib or sunitinib.

Table 12 presents the recommended screening tests for GIST patients. 


\section{References}

1. Rutkowski P. (ed.) Mięsaki tkanek miękkich. Via Medica, Gdańsk 2015

2. Wojciechowska U, Didkowska J. Nowotwory w Polsce w 2012 roku. Nowotwory. Journal of Oncology. 2013; 63(3): 197-216, doi: 10.5603/njo.2013.0001

3. ESMO/European Sarcoma Network Working Group. Soft tissue and visceral sarcomas: ESMO Clinical Practice Guidelines for diagnosis, treatment and follow-up. Ann Oncol. 2014; 25 Suppl 3 iii102-iii112, doi: 10.1093/annonc/mdu254, indexed in Pubmed: 25210080.

4. Fletcher CDM, Bridge JA, Hogendoorn PCW. WHO Classification of tumours of soft tissue and bone. Lyon: IARC. 2013

5. Lasota J. Molecular genetics in soft tissue tumors. In: Miettinen M. ed. Modern soft tissue pathology. Tumors and non-neoplastic conditions. University Press, Cambridge 2010: 127-180.

6. Soft tissue sarcoma. In: Edge SB, Byrd DR, Compton CC. ed. AJCC Cancer Staging Manual. Springer, New York 2010: 291-296.

7. Amin MB, Edge S, Greene FA. Cancer Staging Manual, 8th edition Springer International Publishing, Cham 2017.

8. Bonvalot S, Miceli R, Berselli M, et al. Aggressive surgery in retroperitoneal soft tissue sarcoma carried out at high-volume centers is safe and is associated with improved local control. Ann Surg Oncol. 2010; 17(6): 1507-1514, doi: 10.1245/s10434-010-1057-5, indexed in Pubmed: 20393803

9. Gronchi A, Miceli R, Colombo C, et al. Frontline extended surgery is associated with improved survival in retroperitoneal low- to intermediate-grade soft tissue sarcomas. Ann Oncol. 2012; 23(4): 1067-1073, doi: 10.1093/annonc/mdr323, indexed in Pubmed: 21765179.

10. Alektiar K. Soft-Tissue Sarcoma. Clinical Radiation Oncology. 2016 1345-1372.e4, doi: 10.1016/b978-0-323-24098-7.00065-4.

11. Rossi CR, Vecchiato A, Mastrangelo G, et al. Adherence to treatment guidelines for primary sarcomas affects patient survival: a side study of the European CONnective TIssue CAncer NETwork (CONTICANET) Ann Oncol. 2013; 24(6): 1685-1691, doi: 10.1093/annonc/mdt031, indexed in Pubmed: 23446092.

12. Rosenberg SA, Tepper J, Glatstein E, et al. The treatment of soft-tissue sarcomas of the extremities: prospective randomized evaluations of (1) limb-sparing surgery plus radiation therapy compared with amputation and (2) the role of adjuvant chemotherapy. Ann Surg. 1982; 196(3): 305-315, indexed in Pubmed: 7114936.

13. Yang JC, Chang AE, Baker AR, et al. Randomized prospective study of the benefit of adjuvant radiation therapy in the treatment of soft tissue sarcomas of the extremity. J Clin Oncol. 1998; 16(1): 197-203, doi: 10.1200/JCO.1998.16.1.197, indexed in Pubmed: 9440743

14. Pisters PW, Harrison LB, Leung DH, et al. Long-term results of a prospective randomized trial of adjuvant brachytherapy in soft tissue sarcoma. J Clin Oncol. 1996; 14(3): 859-868, doi: 10.1200/JCO.1996.14.3.859, indexed in Pubmed: 8622034

15. O'Sullivan B, Davis AM, Turcotte R, et al. Preoperative versus postoperative radiotherapy in soft-tissue sarcoma of the limbs: a randomised trial. Lancet. 2002; 359(9325): 2235-2241, doi: 10.1016/S01406736(02)09292-9, indexed in Pubmed: 12103287.

16. Koseła-Paterczyk H, Szacht M, Morysiński T, et al. Preoperative hypofractionated radiotherapy in the treatment of localized soft tissue sarcomas. Eur J Surg Oncol. 2014; 40(12): 1641-1647, doi: 10.1016/j. ejso.2014.05.016, indexed in Pubmed: 25282099.

17. Pervaiz N, Colterjohn N, Farrokhyar F, et al. A systematic meta-analysis of randomized controlled trials of adjuvant chemotherapy for localized resectable soft-tissue sarcoma. Cancer. 2008; 113(3): 573-581, doi 10.1002/cncr.23592, indexed in Pubmed: 18521899.

18. Gronchi A, Frustaci S, Mercuri M, et al. Short, full-dose adjuvant chemotherapy in high-risk adult soft tissue sarcomas: a randomized clinical trial from the Italian Sarcoma Group and the Spanish Sarcoma Group. J Clin Oncol. 2012; 30(8): 850-856, doi: 10.1200/JCO.2011.37.7218, indexed in Pubmed: 22312103.

19. Gronchi A, Ferrari S, Quagliuolo V, et al. Histotype-tailored neoadjuvant chemotherapy versus standard chemotherapy in patients with high-risk soft-tissue sarcomas (ISG-STS 1001): an international, open-label, randomised, controlled, phase 3, multicentre trial. Lancet Oncol. 2017; 18(6): 812-822, doi: 10.1016/S1470-2045(17)30334-0, indexed in Pubmed: 28499583.

20. Issels RD, Lindner LH, Verweij J, et al. European Organisation for Research and Treatment of Cancer Soft Tissue and Bone Sarcoma Group (EORTC-STBSG), European Society for Hyperthermic Oncology (ESHO). Neo-adjuvant chemotherapy alone or with regional hyperthermia for localised high-risk soft-tissue sarcoma: a randomised phase 3 multicentre study. Lancet Oncol. 2010; 11(6): 561-570, doi: 10.1016/S1470-2045(10)70071-1, indexed in Pubmed: 20434400.
21. Trabulsi NH, Patakfalvi L, Nassif MO, et al. Hyperthermic isolated limb perfusion for extremity soft tissue sarcomas: systematic review of clinical efficacy and quality assessment of reported trials. J Surg Oncol. 2012; 106(8): 921-928, doi: 10.1002/jso.23200, indexed in Pubmed: 22806575

22. Antman K, Crowley J, Balcerzak SP, et al. An intergroup phase III randomized study of doxorubicin and dacarbazine with or without ifosfamide and mesna in advanced soft tissue and bone sarcomas. J Clin Oncol. 1993; 11(7): 1276-1285, doi: 10.1200/JCO.1993.11.7.1276, indexed in Pubmed: 8315425.

23. Judson I, Verweij J, Gelderblom H, et al. European Organisation and Treatment of Cancer Soft Tissue and Bone Sarcoma Group. Doxorubicin alone versus intensified doxorubicin plus ifosfamide for first-line treatment of advanced or metastatic soft-tissue sarcoma: a randomised controlled phase 3 trial. Lancet Oncol. 2014; 15(4): 415-423, doi: 10.1016/S1470-2045(14)70063-4, indexed in Pubmed: 24618336.

24. Maki RG, Wathen JK, Patel SR, et al. Randomized phase II study of gemcitabine and docetaxel compared with gemcitabine alone in patients with metastatic soft tissue sarcomas: results of sarcoma alliance for research through collaboration study 002 [corrected]. J Clin Oncol. 2007: 25(19): 2755-2763, doi: 10.1200/JCO.2006.10.4117, indexed in Pubmed: 17602081

25. Demetri GD, von Mehren M, Jones RL. Efficacy and safety of trabectedin or dacarbazine for metastatic liposarcoma or leiomyosarcoma after failure of conventional chemotherapy: results of a phase iii randomized multicenter clinical trial. J Clin Oncol. 2016; 34(8): 786-793.

26. van der Graaf WTA, Blay JY, Chawla SP, et al. EORTC Soft Tissue and Bone Sarcoma Group, PALETTE study group. Pazopanib for metastatic soft-tissue sarcoma (PALETTE): a randomised, double-blind, placebo-controlled phase 3 trial. Lancet. 2012; 379(9829): 1879-1886, doi: 10.1016/S0140-6736(12)60651-5, indexed in Pubmed: 22595799

27. Rutkowski P, Van Glabbeke M, Rankin CJ, et al. European Organisation for Research and Treatment of Cancer Soft Tissue/Bone Sarcoma Group, Southwest Oncology Group. Imatinib mesylate in advanced dermatofibrosarcoma protuberans: pooled analysis of two phase II clinical trials. J Clin Oncol. 2010; 28(10): 1772-1779, doi: 10.1200/JCO.2009.25.7899, indexed in Pubmed: 20194851.

28. Blay JY, Leahy MG, Nguyen BB, et al. Randomised phase III trial of trabectedin versus doxorubicin-based chemotherapy as first-line therapy in translocation-related sarcomas. Eur J Cancer. 2014; 50(6): 1137-1147, doi: 10.1016/j.ejca.2014.01.012, indexed in Pubmed: 24512981.

29. Cesne ALe, Blay JY, Cupissol D, et al. Results of a prospective randomized phase III T-SAR trial comparing trabectedin vs best supportive care (BSC) in patients with pretreated advanced soft tissue sarcoma (ASTS). Annals of Oncology. 2016; 27(suppl 6), doi: 10.1093/annonc/mdw388.02

30. Le Cesne A, Blay JY, Domont J, et al. Interruption versus continuation of trabectedin in patients with soft-tissue sarcoma (T-DIS): a randomised phase 2 trial. Lancet Oncol. 2015; 16(3): 312-319, doi: 10.1016/S14702045(15)70031-8, indexed in Pubmed: 25680558.

31. Demetri GD, Schöffski P Grignani G, et al. Eribulin versus dacarbazine in previously treated patients with advanced liposarcoma or leiomyosarcoma: a randomised, open-label, multicentre, phase 3 trial. Lancet. 2016; 387(10028): 1629-1637, doi: 10.1016/S0140-6736(15)01283-0, indexed in Pubmed: 26874885.

32. Tap WD, Jones RL, Van Tine BA, et al. Olaratumab and doxorubicin versus doxorubicin alone for treatment of soft-tissue sarcoma: an open-label phase $1 \mathrm{~b}$ and randomised phase 2 trial. Lancet. 2016: 388(10043): 488-497, doi: 10.1016/S0140-6736(16)30587-6, indexed in Pubmed: 27291997.

33. Gounder MM, Stacchiotti S, Schöffski $P$, et al. Phase 2 multicenter study of the EZH2 inhibitor tazemetostat in adults with INI1 negative epithelioid sarcoma (NCT02601950). J Clin Oncol. J Clin Oncol. 2017; Suppl(abstract 11058)

34. Voutsadakis IA, Zaman K, Leyvraz S. Breast sarcomas: current and future perspectives. Breast. 2011; 20(3): 199-204, doi: 10.1016/j. breast.2011.02.016, indexed in Pubmed: 21398126.

35. Bousquet $\mathrm{G}$, Confavreux $\mathrm{C}$, Magné N, et al. Outcome and prognostic factors in breast sarcoma: a multicenter study from the rare cancer network. Radiother Oncol. 2007; 85(3): 355-361, doi: 10.1016/j. radonc.2007.10.015, indexed in Pubmed: 18023492

36. Rutkowski P, Śpiewankiewicz B, Koseła H, et al. Sarcoma of the uterus: diagnostic and therapeutic recommendations. Current Gynecologic Oncology. 2013; 11(1): 24-32, doi: 10.15557/cgo.2013.0002.

37. McMeekin DS. Sarcoma of the uterus. In: DiSaia P, Creasman W. ed. Clinical gynecologic oncology. Eight edition Elsevier 2013: 175-188.

38. Reed NS, Mangioni C, Malmström H, et al. European Organisation for Research and Treatment of Cancer Gynaecological Cancer Group. 
Phase III randomised study to evaluate the role of adjuvant pelvic radiotherapy in the treatment of uterine sarcomas stages I and II: an European Organisation for Research and Treatment of Cance Gynaecological Cancer Group Study (protocol 55874). Eur J Cancer. 2008; 44(6): 808-818, doi: 10.1016/j.ejca.2008.01.019, indexed in Pubmed: 18378136.

39. Gronchi A, Colombo C, Pechoux CLe, et al. Sporadic desmoid-type fibromatosis: a stepwise approach to a non-metastasising neoplasm-a position paper from the Italian and the French Sarcoma Group. Annals of Oncology. 2013; 25(3): 578-583, doi: 10.1093/annonc/mdt485.

40. Kasper B, Baumgarten C, Bonvalot S, et al. Desmoid Working Group. Management of sporadic desmoid-type fibromatosis: a European consensus approach based on patients' and professionals expertise - a sarcoma patients EuroNet and European Organisation for Research and Treatment of Cancer/Soft Tissue and Bone Sarcoma Group initiative. Eur J Cancer. 2015; 51(2): 127-136, doi: 10.1016/j. ejca.2014.11.005, indexed in Pubmed: 25434922.

41. Rutkowski P, Lugowska I. Follow-up in soft tissue sarcomas. Memo. 2014; 7(2): 92-96, doi: 10.1007/s12254-014-0146-8, indexed in Pubmed: 25089160.

42. Miettinen M, Lasota J. Gastrointestinal stromal tumors - definition, clinical, histological, immunohistochemical, and molecular genetic features and differential diagnosis. Virchows Arch. 2001; 438(1): 1-12, indexed in Pubmed: 11213830.

43. ESMO/European Sarcoma Network Working Group, ESMO/European Sarcoma Network Working Group. Gastrointestinal stromal tumors: ESMO Clinical Practice Guidelines for diagnosis, treatment and follow-up. Ann Oncol. 2012; 23 Suppl 7: vii49-vii55, doi: 10.1093/annonc/mds252, indexed in Pubmed: 22997454.

44. Rutkowski P, Gronchi A, Hohenberger P, et al. Neoadjuvant imatinib in locally advanced gastrointestinal stromal tumors (GIST): the EORTC STBSG experience. Ann Surg Oncol. 2013; 20(9): 2937-2943, doi: 10.1245/s10434-013-3013-7, indexed in Pubmed: 23760587.

45. Rutkowski P, Wozniak A, Dębiec-Rychter M, et al. Clinical utility of the new American Joint Committee on Cancer staging system for gastrointestinal stromal tumors: current overall survival after primary tumor resection. Cancer. 2011; 117(21): 4916-4924, doi: 10.1002/cncr.26079, indexed in Pubmed: 21456019.

46. Rutkowski P, Nowecki ZI, Michej W, et al. Risk criteria and prognostic factors for predicting recurrences after resection of primary gastrointestinal stromal tumor. Ann Surg Oncol. 2007; 14(7): 2018-2027, doi: 10.1245/s10434-007-9377-9, indexed in Pubmed: 17473953.
47. Joensuu $H$, Eriksson M, Sundby Hall K, et al. Adjuvant Imatinib for High-Risk Gl Stromal Tumor: Analysis of a Randomized Trial. J Clin Oncol. 2016; 34(3): 244-250, doi: 10.1200/JCO.2015.62.9170, indexed in Pubmed: 26527782.

48. Blanke CD, Demetri GD, von Mehren M, et al. Long-term results from a randomized phase II trial of standard- versus higher-dose imatinib mesylate for patients with unresectable or metastatic gastrointestinal stromal tumors expressing KIT. J Clin Oncol. 2008; 26(4): 620-625, doi: 10.1200/JCO.2007.13.4403, indexed in Pubmed: 18235121.

49. Heinrich MC, Rankin C, Blanke CD, et al. Efficacy and safety of imatinib mesylate in advanced gastrointestinal stromal tumors. N Engl J Med. 2002; 347(7): 472-480, doi: 10.1056/NEJMoa020461, indexed in Pubmed: 12181401.

50. Heinrich MC Corless CL, Demetri GD, et al. Kinase mutations and imatinib response in patients with metastatic gastrointestinal stromal tumor. J Clin Oncol. 2003; 21 (23): 4342-4349, doi: 10.1200/JCO.2003.04.190, indexed in Pubmed: 14645423.

51. Demetri GD, van Oosterom AT, Garrett CR, et al. Efficacy and safety of sunitinib in patients with advanced gastrointestinal stromal tumour after failure of imatinib: a randomised controlled trial. Lancet. 2006; 368(9544): 1329-1338, doi: 10.1016/S0140-6736(06)69446-4, indexed in Pubmed: 17046465

52. Reichardt P, Kang YK, Rutkowski P, et al. Clinical outcomes of patients with advanced gastrointestinal stromal tumors: safety and efficacy in a worldwide treatment-use trial of sunitinib. Cancer. 2015; 121(9): 1405-1413, doi: 10.1002/cncr.29220, indexed in Pubmed: 25641662.

53. Demetri GD, Reichardt P, Kang YK, et al. GRID study investigators. Efficacy and safety of regorafenib for advanced gastrointestinal stromal tumours after failure of imatinib and sunitinib (GRID): an international, multicentre, randomised, placebo-controlled, phase 3 trial. Lancet. 2013; 381(9863): 295-302, doi: 10.1016/S0140-6736(12)61857-1, indexed in Pubmed: 23177515.

54. Montemurro M, Gelderblom H, Bitz U, et al. Sorafenib as third- or fourth-line treatment of advanced gastrointestinal stromal tumour and pretreatment including both imatinib and sunitinib, and nilotinib: A retrospective analysis. Eur J Cancer. 2013; 49(5): 1027-1031, doi: 10.1016/j.ejca.2012.10.009, indexed in Pubmed: 23140824.

55. Bauer S, Rutkowski P, Hohenberger P, et al. Long-term follow-up of patients with GIST undergoing metastasectomy in the era of imatinib analysis of prognostic factors (EORTC-STBSG collaborative study). Eur J Surg Oncol. 2014; 40(4): 412-419, doi: 10.1016/j.ejso.2013.12.020, indexed in Pubmed: 24491288. 